\title{
Aspectos do uso da descarga do órgào elétrico e eletrorrecepção nos Gymnotoidei e outros peixes amazônicos
}

\author{
T. H. Bullock ${ }^{a}{\left({ }^{*}\right), \text { N. Fernandes-Souza }}^{b}$, W. Graf ${ }^{c}$, W. Helligenberg $a$, G, Langner ${ }^{d}$, D.L.Meyer $c$, F. Pimentel- \\ Souza $^{b}{\left({ }^{* \star}\right), \text { H. Scheich }}^{d}$ e T.A. Viancour $a$
}

\section{Resumo}

Após fazer-se um estudo sobre aspectos gerais de familias, gêneros e algumas espécies de Gymnotoidei e outros peixes elétricos amazônicos, bem como sobre seus habitats e hábitos de vida, analisam-se os órgãos elétricos e respectivas descargas em várias espécies. Procuram estabelecer-se as funçōes da descarga do órgão elétrico, (DOE) na vída do animal. correlacionando-se a mesma com o comportamento e outros eventos. Em seguida, estuda-se a eletrorrecepção, seus órgãos dos sentidos especiais e processamento cerebral, inclusive o uso de eletrorrecepção por peixes năo elétricos. Conclui-se o trabalho, interpretando-se o possivel significado ecológico e prático dos fatos observados.

\section{INTRODUÇÃo}

A bacia amazônica é o ambiente natural de um grande e notável grupo de espécies de peixes, os Gymnotoidei, os quais possuem, todos, órgãos elétricos. Além da conhecida enguia elétrica, muitas outras espécies semelhantes dentre incontáveis milhōes de peixes. estão descarregando fracos pulsos elétricos na água, noite e dia, durante toda a vida, numa freqüência de poucos até mais de mil pulsos por segundo.

O Electrophorus electricus, a enguia legendária, desperta um especial interesse. Como os outros peixes fortemente elétricos, o "catfish" do Nilo, Malapterurus e a raia elétrica marinha, Torpedo - os quais pertencem a dois grupos não relacionados - sua estranha capacidade de excitar tanto a sensação quanto a contração foi percebida, senão compreendida, muito antes de Benjamim Franklin ter empinado seu papagaio durante uma tempestade. O poder da enguia elétrica tem despertado tanto respeito que, entre os caboclos que vivem ro longo dos rios do Amazonas, ainda existe a crença de que sua descarga ao redor da base de uma palmeira pode fazer com que as frutas caiam. (')

Igualmente notáveis são as outras espécies de gimnotóides com nomes comuns, como sarapó, ituí, tovira, peixe espada e espírito-negro. A descarga de seus órgãos elétricos (daqui para frente apenas DOE) é demasiado fraca para ser sentida, muito menos para poder ser ofensiva ou defensiva, e é usada para dois outros propósitos - para a detecção de objetos - alimento, plantas, obstáculos, cavidades ou de outra espécie. Estas funçöes requerem um sistema nervoso altamente desenvolvido para a percepçăo de mudanças muito pequenas no fraco campo elétrico da DOE e também para o controle da DOE, pulso por pulso.

A capacidade para detectar campos elétricos extremamente fracos, na água, não está confinada nas poucas familias que pessuem órgãos elétricos e geram DOEs. Vários grandes grupos de peixes - embora seja minoria entre todos os peixes - são receptores mas näo emissores, pelo menos de pulsos răo especializados. Todos os peixes, como de fato todos os seres vivos, dissipam alguma corrente elétrica, ao menos como uma espécie de escapamento dos processos internos, e este pequeniníssimo sínal é usado pelos peixes eletrorreceptivos para encontrar a presa. No Amazonas, nove familias de Siluroidei (em in-

(*) - Coordenador do artigo de revisão.

[") - Supervisor da traduçăo do original em inglês, a cargo do pessoal do INPA.

[1] - Temos sido questionados a respeito da plausibilidade deste fato. Considerando que apenas uma fraçāo minima da corrente do peixe deverá passar através de uma determinada regiăo como tecido de sustentaçẩo do fruto, é altamente improvável que estes pulsos elétricos, que são de curta duraçáo, possam exercer tal efeito.

(a) University of California, San Diego, CA, US

(b) Universidade Federal de Minas Gerais, MG, Brasil

(c) University of Goettingen, Germany

(d) Technische Hochschule Darmstadt, Germany 
glês "catfish", no Brasil surubim, cuiú-cuiú, caparari, bagre, piraíba, etc.) mais os Elasmobranchia residentes e visitantes (tubarōes e raias) possuem aielicados eletrossensores na pele.

Este trabalho tem por objetivo introduzir um aspecto raro mas significativo de comportamento e ecologia. É uma atraente pesquisa em prática na Alemanha, na Holanda, na Inglaterra, na França, nos Estados Unidos, na Rússia e em outros locais, inclusive no Brasil. Cientistas que vivem perto dos habitats naturais do peixe elétrico têm oportunidades únicas para aplicar estas especializações a problemas gerais da biologia de peixes e águas naturais.

Aspectos Gerais de famílias, GÊNeros E ALGUMAS ESPÉCIES

\section{A. GYMNOTOIDEI}

Todos os peixes elétricos de água doce do Novo Mundo pertencem a esta subordem da ordem Cypriniformes e aparentemente todos os membiros da subordem são elétricos. Para o propósito de nosso trabalho, é importante dizer que aparentemente todas estas espécies também possuem eletrorreceptores a julgar pela amostra das espécies, que têm sido estudadas e que săo algumas em cada uma das familias conhecidas. Todos os gimnotóides săo delgados e alongados, sem nadadeira dorsal mas com uma nadadeira anal extraordinariamente longa, lembrando a lâmina de uma faca pontuda daí o nome de "peixe-espada" (Fig. 1). Uma família tem a forma de uma enguia.

Seis famílias são reconhecidas pelas mais recentes autoridades (Mago-Lecia, 1976), conforme relação abaixo, com alguns de seus gêneros representativos.

1. Electrophoridae. A enguia-elétrica, compreendendo o gênero Electrophorus ("poraquê"), forma uma família própria. É o maior gimnotóide, o-único com alta voltagem, capaz portanto de usar a descarga para ataque ofensivo ou defensivo. Possui também órgãos elé- tricos seperados de baixa voltagem, que emitem pulsos numa baixa freqüência, irregularmente, para eletrolocalização e eletrocomunicação .

2. Gymnotoidae. O gênero comum Gymnotus (sarapó ou carapó) é um grupo euritópico, largamente distribuído, de espécies muito semelhantes. G. carapo tem sido muito estudado. É um peixe de pulsos (definido mais abaixo) de freqüência média (cerca de 50 por segundo) e pode atingir mais de $45 \mathrm{~cm}$, alimenta-se não apenas de invertebrados mas também de peixes de vários centímetros de comprimento.

3. Rhamphichthydae. Este grupo de peixes de freqüência média inclui o gênero Rhamphichthys, que atinge mais de um metro de comprimento, e Gymnorhamphichthys, o mais nitidamente circadiano de um grupo geralmente noturno. Ambos os gêneros normalmente ficam imóveis sobre o fundo, durante o período de repouso, sem procurar manter uma postura com o dorso para cima.

4. Hypopomidae. Este é um grupo mais diversificado de peixes de freqüência de pulso: baixa $(<30$ por segundo), média e alta ( $>100$ por segundo), incluindo muitas espécies de Hypopomus, Hypopygus, Parupygus e Steatogenys. Existe uma acentuada diferença entra as espécies na taxa de repetição e uma tendência para correlacionar inversamente este fato com a duração do pulso; permitindo presumivelmente que, espécies de pulsos simpátricos, reconheçam os sinais específicos de sua própria espécie.

5. Sternopygidae. Esta é a primeira família de espécies produtoras de ondas (em oposição a pulsos em nossa lista). Sternopygus é um gênero de baixa freqüência (70-140 por segundo), portanto com o pulso mais longo da subordem (acima de $7 \mathrm{~ms}$ ). Eigenmannia de várias espécies têm uma descarga de menos de 200 a mais de 500 por segundo, e são bons exemplos de espécies que ficam suspensos na água, com contínuas ondulaçōes da nadadeira anal. Uma onda caudal e outra rostral encontrando-se e cancelando-se na parte me- 


\section{APTERONOTIDAE}

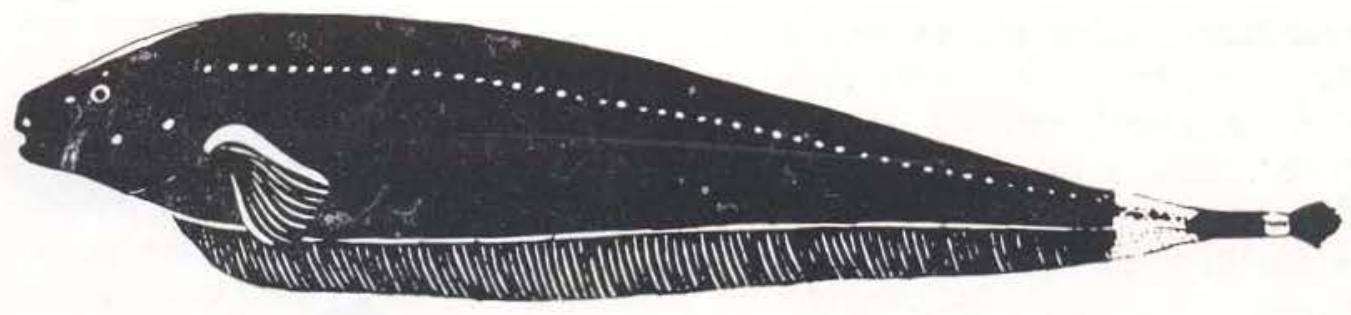

APTERONOTUS

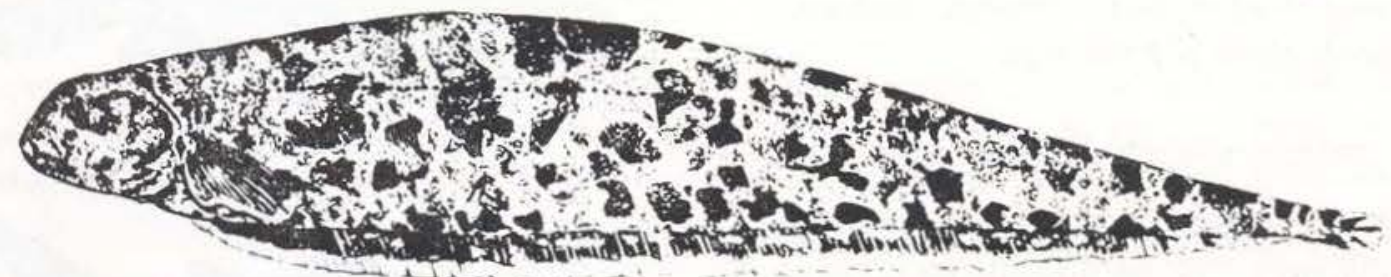

ADONTOSTERNARCHUS

\section{STERNOPYGIDAE}

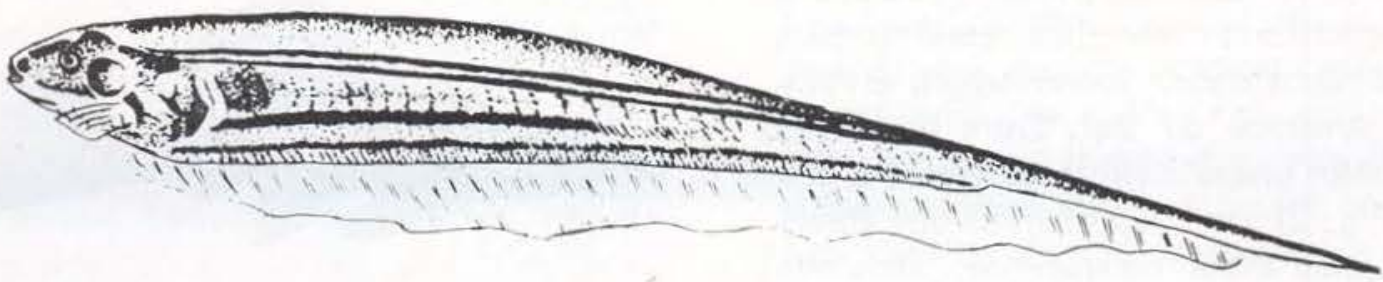

EIGENMANNIA

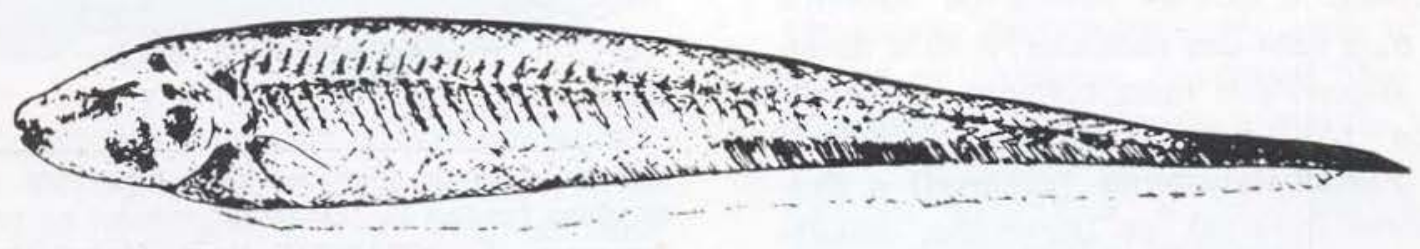

\section{STERNOPYGUS}

Fig. 1 - Peixes gimnotóides. São mostrados exemplos de 4 gêneros em 2 famílias comuns no sistema do Amazonas 
diana do peixe. Este gênero também é um bom exemplo de grupo gregário, já que a maioria dos outros gimnotóides é ierritorial ou mantém espaçamentos entre si.

6. Apteronotidae. Estes são os peixes de alta freqüência, produtores de ondas (cerca de 700-2100 por segundo), notáveis também por possuírem os rítmos mais regulares, em repouso, conhecidos no mundo vivo. As pequenas modulações de freqüência, sob controle cerebral, possuem significado comunicativo. Gêneros comuns na Amazônia incluem Apteronotus, (antigamente Sternarchus), Sternarchella, Sternarchorhynchus, Sternarchorhamphus, Sternarchogiton e Porotergus.

\section{B. OUTROS PEIXES ELETRORRECEPTIVOS}

Órgãos dos sentidos especializacios na detecção de fracos campos elétricos na água têm sido "inventados" pela evoluçāo muitas vezes - e não apenas nos vários grupos não relacionados de peixes que desenvolveram órgãos elétricos (Rajidae, Torpedinae dos Elasmobranchia; a família Astroscopidae de teleósteos marinhos; os teleósteos africanos de água doce dos Mormyridae, Gymnarchidae e Malapteruridae, os teleósteos de água doce da América tropical da superfamília Gymnotoidei), mas também em outros. Estes incluem todos os outros Elasmobranchia (tubarões e raias), principalmente marinhos, mas também as raias de água doce, Potamotrygon e Paratrygon da América do Sul. Entre os peixes ósseos, o maior grupo eletrorreceptivo é o dos Siluroidei (Fig. 2), uma superfamília que abrange mais de uma dúzia de familias, incluindo nove na América do Sul e milhares de espécies. De acordo com Bates (1964), a fauna extraordinariamente rica de peixes da América do Sul (i.e. a lista das espécies) é $40 \%$ de siluróicies. Alguns dos mais comuns ou melhor conhecidos são os Pimelodidae, incluindo Sorubim, Pseudoplatystoma (capararí) e Brachiplatystoma (piraíba), os Doradidae, incluindo Doras e Oxydoras (cuiú-cuiú), os Callichthyidae, incluindo Corydoras, os Loricariidae (cascudos), incluindo Ancistrus (barbadinhos) e Plecostomus, os Trichomycteridae (Pygidiidae), incluindo Vandellia (candiru).
Entre outros peixes, todios da América do Sul e outras partes, existem evidências, sugestivas ou conclusivas, de que a eletrorre-
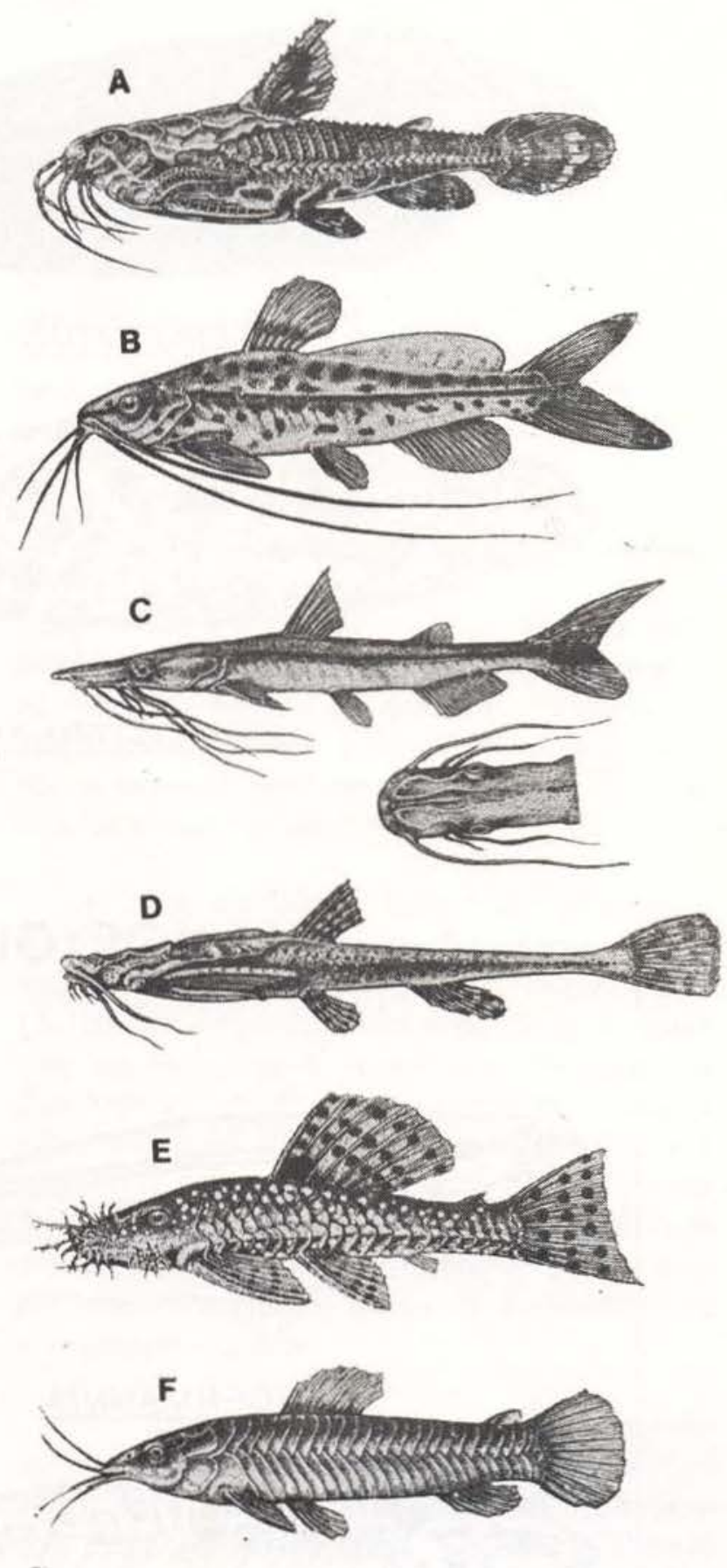

Fig. 2 - Peixes siluróides. São mostrados exemplos de várias familias de "catfishes" comuns no sıstema do Amazonas. A. DORADIDAE, Doras (Acanthodoras) spinosissimus. B. PIMELODIDAE, Rhamdia sebae e C. Sorubim lima (com vista dorsal da cabeça). D. BUNOCEPHALIDAE, Bunocephalus bicolor. E. LORICARIIDAE, Ancistrus cirrhosus. F. CALLICHTHYIDAE, Callichthys callichthys (de Sterba, 1963). 
cepção também ocorre nos Chondrustei, incluindo Scaphirhunchus (esturjão), Polyodon ("spoonbill"), Dipnoi, incluindo Lepidosiren (pirambóia, peixe pulmonado e possivelmente mesmo em alguns anfíbios da ordem Gymnophiona $(=$ Apoda, Caeciliidae, cobra de duas cabeças).

A eletrorrecepção não é conhecida em invertebrados ou em outros vertebrados aquáticos. Em vertebrados terrestres, incluindo a espécie humana, há alguma razão para crer que, mesmo se nenhum órgão de sentido está presente para detectar campos elétricos aplicados externamente, pode ser normal algumas células do sistema nervoso serem influenciadas por fracas correntes no tecido. Portanto, os mecanismos que estudamos nos estranhos peixes podem ter um mais amplo interesse neurobiológico.

ASPECTOS GERAIS DE HABITATS E HÁBITOS DE VIDA DOS GYMNOTOIDEI

Entre as seis familias e dezenas de gêneros existem espécies que vivem em igarapés e rios, em lagos calmos e igapós, sobre fundo de areia e sobre lodo, em água branca, água negra e água azul (cristalina), em estuários de alta condutibilidade (ilha de Marajó: $>2000$ $\mu$ mhos) e em águas de baixo teor mineral, de condutibilidade extremamente baixa $l<10$ $\mu$ mhos). Não quer dizer que os peixes eletrorreceptivos, ou mesmo os chamados peixes-elétricos (por possuirem órgãos elétricos) vivam caracteristicamente em águas opacas, embora, sem dúvida, a maioria dieles o faça. 0 mesmo ocorre também com peixes não-eletrorreceptivos.

Nosso conhecimento da distribuição exata das espécies é tão limitado que não podemos dizer se existem muitas espécies particulares confinadas à água negra ou branca, por exemplo. Podemos dizer que existem muitas que ocorrem tanto em uma quanto em outra, e portanto em águas de condutibilidade relativamente mais baixa e mais alta. Algumas espécies, tais como Electrophorus electricus, Gymnotus carapo, Apteronotus albifrons (mais conhecido no Brasil como ituí-cavalo ou toviracavalo) e Eigenmannia virescens (conhocido como sarapo-branco) parecem ter uma distri- buição geográfica muito ampla. Semi dúvida outras são tão raras quanto locais, mas as amostragens tem sido täo esporádicas e a taxonomia é tão pouco conhecida, que não se pode confirmar esta suposição. É muito necessário que se façam coletas sistemáticas em muitas localidades e habitats, com identificação adequada das espécies.

A maioria das espécies está sujeita a grandes mudanças sazonais, com a subida e a descida nos níveis da água, a inundaçăo de enormes áreas de florestas e mudanças drásticas em tipos e disponibilidade de alimento.

E provável que muitas espécies sejam especialistas alimentares, por exemplo buscando alimento ao redor de folhas de plantas aquáticas ou raízes de plantas flutuantes, ou entre o folhedo do fundo ou no lodo. A julgar pela experiência com os grupos mais bem conhecidos, pode esperar-se que especialistas extremos em alimentos e em associados e inimigos não sejam raros entre os gimnotóides. Todos os gimnotóides parecem ser carnívoros e a maioria alimenta-se de insetos e crustáceos, embora as espécies maiores predem peixes talvez incluindo outros gimnotóides. Electrophorus e Gymnotus apanham e consomem peixes eléiricos pequenos em tanques, mas isto năo nos auxilia muito na estimativa do grau de uma tal predação na natureza.

Sabemos menos ainda a respeito de outros inimigos dos gimnotóides e presumivelmente eles devem precisar escapar de um grande grupo de predadores, como os siluróides. Em várias localidades, métodos de coleta que apanham todos os peixes em vários metros cúbicos de água rasa (cerca de $1 \mathrm{~m}$ de profundidade), trazem um grande número de indivíduos e a maioria deles pode ser gimnotóides. Isto poderia dizer que o grupo possui significado econômico como uma parte substancial da biomassa disponivel para os membros mais altos da cadeia alimentar.

ÓRgÃos ELÉTRICOS E DESCARGA DO ÓRGÃ̃ ELÉTRICO EM VÁRIAS ESPÉCIES

No peixe-elétrico, a descarga elétrica é produzida por uma agregação de tecidos especializados, que constitui o órgão elétrico. A descarga é produzida por células, conhecidas 
como eletrócitos, que são células musculares modificadas, ou, em certos gêneros, neurônios especializados. Os órgãos elétricos formados por eletrócitos derivados de células musculares são "miogênicos" (evoluídos a partir do músculo). Os que são formados por eletrócitos derivados de neurônios são "neurogênicos" (Fig. 3).

Os órgãos elétricos miogênicos evoluiram independentemente em vários e diferentes grupos de peixes. Na família Torpedinidae dos elasmobrânquios (raias), os eletrócitos evoluíram a partir da musculatura branquial. Outras familias de elasmobrânquios, os Rajidae (raias), possuem órgãos elétricos derivados dos músculos da cauda. No siluróide Malapterurus, o "catfish" elétrico, o órgão evoluiu desde o músculo peitoral. A família Astroscopidae de teleósteos marinhos, os "stargazers". tem órgãos evoluidos a partir de músculos normalmente envolvidos no controle do movimen- to do olho. A maioria das espécies de peixe elétrico pertence aos Mormyriformes africanos e aos Gymnotoidei da América do Sul; nesses grupos os órgãos miogênicos evoluiram desde músculos axial e da cauda.

Órgãos elétricos neurogênicos ocorrem apenas na familia Apteronotidae (inicialmente Sternarchidae) da superfamília Gymnotoidei da América do Sul (Fig. 3B). Estes órgãos são um resultado da evolução secundária de órgãos miogênicos. Isto ocorreu por degeneração da parte miogênica do órgão e especialização dos neurônios que inicialmente o enervaram.

Órgãos miogênicos são capazes de produzir descargas mais poderosas de que os órgãos neurogênicos. Na enguiâ-elétrica (Electrophorus), o órgão miogênico pode descarregar rapidamente $(1 \mathrm{~ms})$ uma corrente de 1 ampère numa voltagem de 500 volts (Fig. $3 \mathrm{~A}$ ).
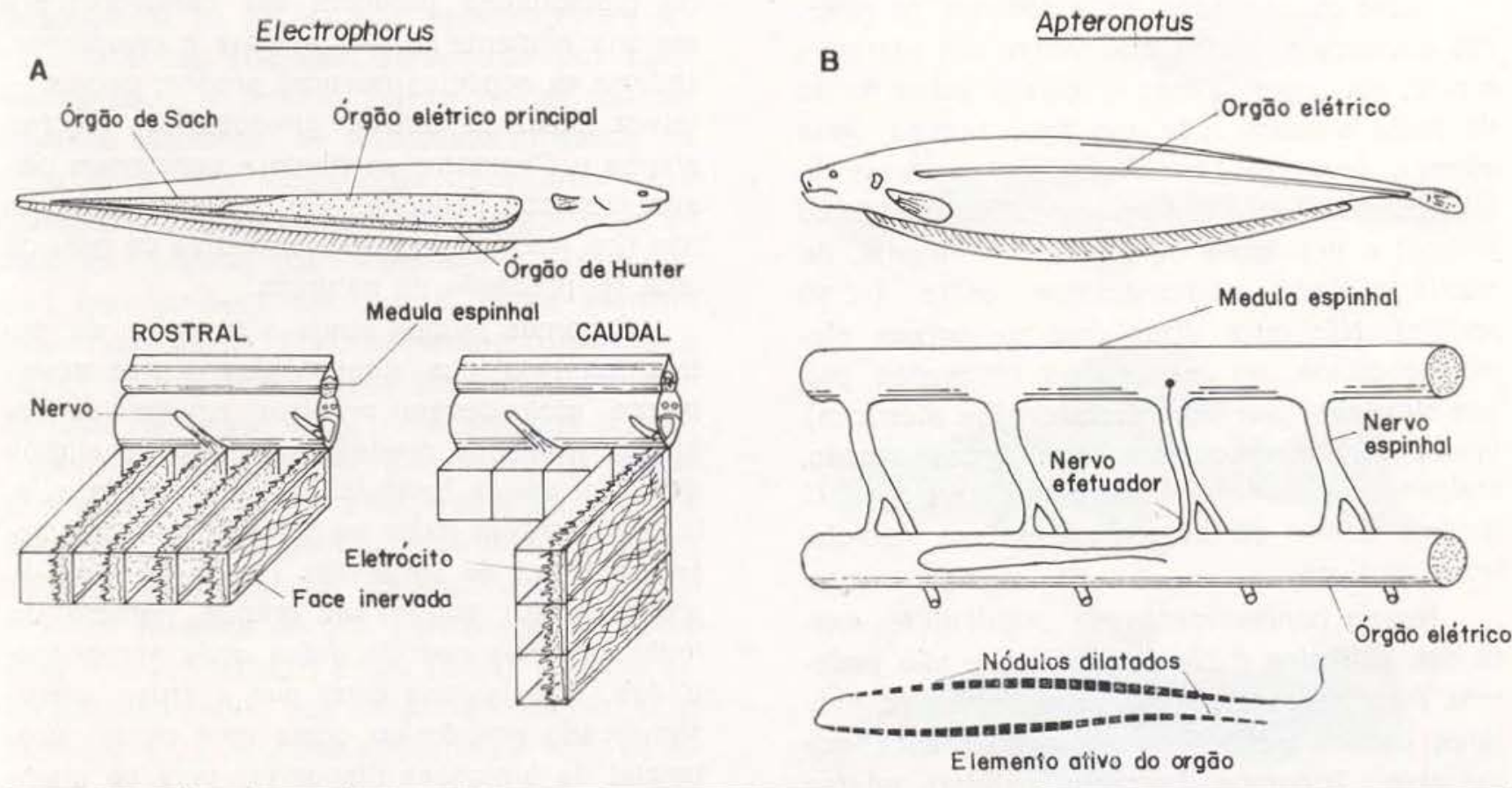

Fig. 3 - Órgãos elétricos. São mostrados esquematicamente exemplos das células geradoras de corrente e sua inervação em 2 tipos muito diferentes de órgãos elétríccs, ambos dos gimnotóides. A. A enguia elétrica com seus órgãos de alta e baixa voltagem; o esquema em maior aumento mostra os compartimentos do tecido conectivo organizado serialmente, cada um contendo uma camada de eletrócitos com uma especialização de suas superfícies rostral e caudal, de tal modo que apenas uma é despolarizada pela chegada do impulso nervoso. Cada uma destas membranas pode contribuir com mais de 0,IV (de Altamirano et al., 1953. B. O ituí-cavalo, uma espécie onduladora de alta freqüência e baixa voltagem; seu órgão consiste de terminaçōes nervosas especializadas dos axônios efetuadores. Os nervos repetidos a cada segmento vertebral, orientados na mesma direção adicionam a corrente de seus grandes nódulos de Ranvier (de Bennett, 1971) 
A vantagem dos órgãos neurogênicos é que eles podem descarregar mais freqüentemente do que os órgãos miogênicos. Isto decorre especialmente devido à capacidade dos neurônios de descarregar em taxas mais altas do que as células musculares. Certas espécies dos apteronotídeos descarregam o órgão elétrico a mais de 1800 vezes por segundo. Fazem isto, dia e noite, durante toda a vida.

Os eletrócitos miogênicos estão, geralmente, entre as maiores células do animal e podem ser em forma de fita, disco ou fuso. Freqüentemente estão dispostos em pilhas, com todas as células orientadas no mesmo sentido. Esta disposição é comum na maioria dos órgãos miogênicos e parece ser um resultado da evolução convergente para permitir uma produção máxima de voltagem pelo órgão.

A enguia-elétrica possui três órgãos elétricos: o de Sach, de Hunter e o órgãc principal. O órgão de Sach e a porção posterior do órgão de Hunter podem ser descarregados sem uma descarga acompanhante do órgão principal. Esta descarga é de baixa amplitude (10 V) e provavelmente é usada mais para a detecção da presa do que para a sua capiura. A notória descarga de 500 volts é produzida quando todos os órgãos descarregam simultaneamente; a maior contribuição é do órgão principal. A maior parte da corrente produzida pela descarga de alta voltagem é canalizada diretamente para o ambiente, reduzindo assim o efeito sobre os tecidos do próprio animal, mas não será surpreendente descobrir que o sistema nervoso central do animal possui adaptações especiais que o tornam tolerante às correntes residuais que devam fluir através dele.

Os eletrócitos ("eletroplacas") do órgão principal na enguia-elétrica são em forma de fita, comprimidas rostro-caudalmente e se estendem lateralmente desde a linha mediana. No adulto existem cerca de 6.000 eletroplacas dispostas em série, em uma coluna rostro-caudal. Existem cerca de 25 dessas colunas dispostas em paralelo para formar o órgão principal. Como a maioria dos outros eletrócitos miogênicos, estes são fisiologicamente polari- zados. As duas faces dos eletrócitos diferem, em termos de sua excitabilidade elétrica. A face posterior dos eletrócitos da enguia é inervada, eletricamente ativa e produz um pico de potencial elétrico devido ao sódio em resposta ao sinal de comando neural. A face anterior possui uma baixa resistência e é eletricamente inexcitável. Combinada com tecidos acessórios isolantes, esta polarizaçăo maximiza a produção da corrente elétrica. Parcialmente, devido a esta propriedade de polarização do eletrócito, o estudo dos vários tipos de órgãos elétricos conduziu a importantes reve!ações a respeito das propriedades das células excitáveis

Em células musculares normais, a contração é iniciada por um rápido evento elétrico que se propaga através da célula. Numa célula única, a amplitude de pico a pico deste evento elétrico é de 80 a $100 \mathrm{mV}$. Este evento, o potencial de ação do músculo é gerado como um resultado de uma estimulação sináptica proveniente de um neurônio que traz informação do sistema nervoso central. A maioria dos eletrócitos, embora não todos, assim como as células musculares das quais săo derivados, produzem um potencial de ação tudo ou nada quando excitados pela informação carregada pelo neurônio inervador. Com os eletrócitos dispostos em série, como pilhas em uma lanterna, e estimulados simultaneamente, as voltagens das descargas dos eletrócitos individuais se somam. Se não ocorre curto circuito das descargas, as 6.000 eletroplacas dispostas serialmente na enguia-elétrica adulta produzirão uma descarga elétrica somada de 480 a 600 volts, o que de fato ocorre.

Com base na descarga de seus órgãos elétricos, os peixes elétricos são classificados como pulsadores ou onduladores (Fig. 4). Os pulsadores produzem uma descarga curta semelhante a um pulso, a intervalos relativamente longos e irregulares. Dependendo da espécie, um pulsador descarregará seu órgão elétrico descle poucas vezes por minuto até mais de 80 por segundo. Os onduladores descarregam numa freqüência constante para produzir um campo elétrico de tipo semelhante à onda senoidal. A regularidade dos intervalos de descarga é notável; é suficientemente estável 
para ser o mais acurado dos relógios biológicos. Dependendo da espécie, um oridulador descaregará cerca de 100 vezes por segundo até mais de 1.800 por segundo.

Os pulsadores possuem uma considerável amplitude para variar a taxa de descarga . Quando eles estão ativos, alimentando-se, perturbados, ou de outro modo excitados, eles podem aumentar a taxa de descarga em várias centenas por cento. Uma razão plausível para este aumento dessa taxa associada ao estímulo, é que o peixe interroga seu ambiente mais freqüentemente para detectar objetos e dessa forma obter a informação necessária à sobrevivência.

Os onduladores normalmente não alteram a taxa de descarga em mais do que cerca de $10 \%$, e apenas sob circunstâncias particulares (ver RES em C do capítulo seguinte). O ondulador constantemente obtém informações

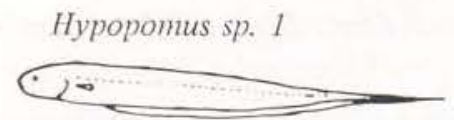

Hypopomus sp. 2

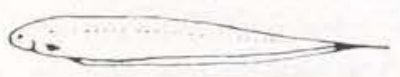

Staetogenes sp.

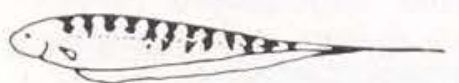

Gymnotus carapo

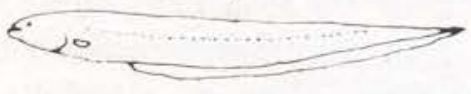

Stemopygus macrurus

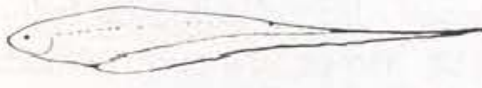

Eigenmannia virescens

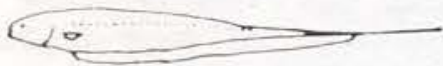

Apteronotus albifrons

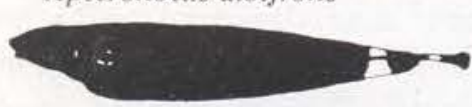

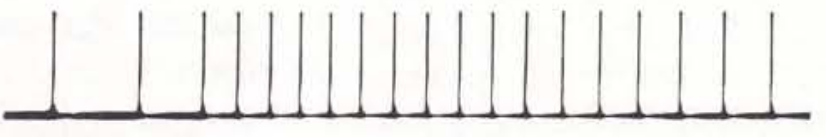
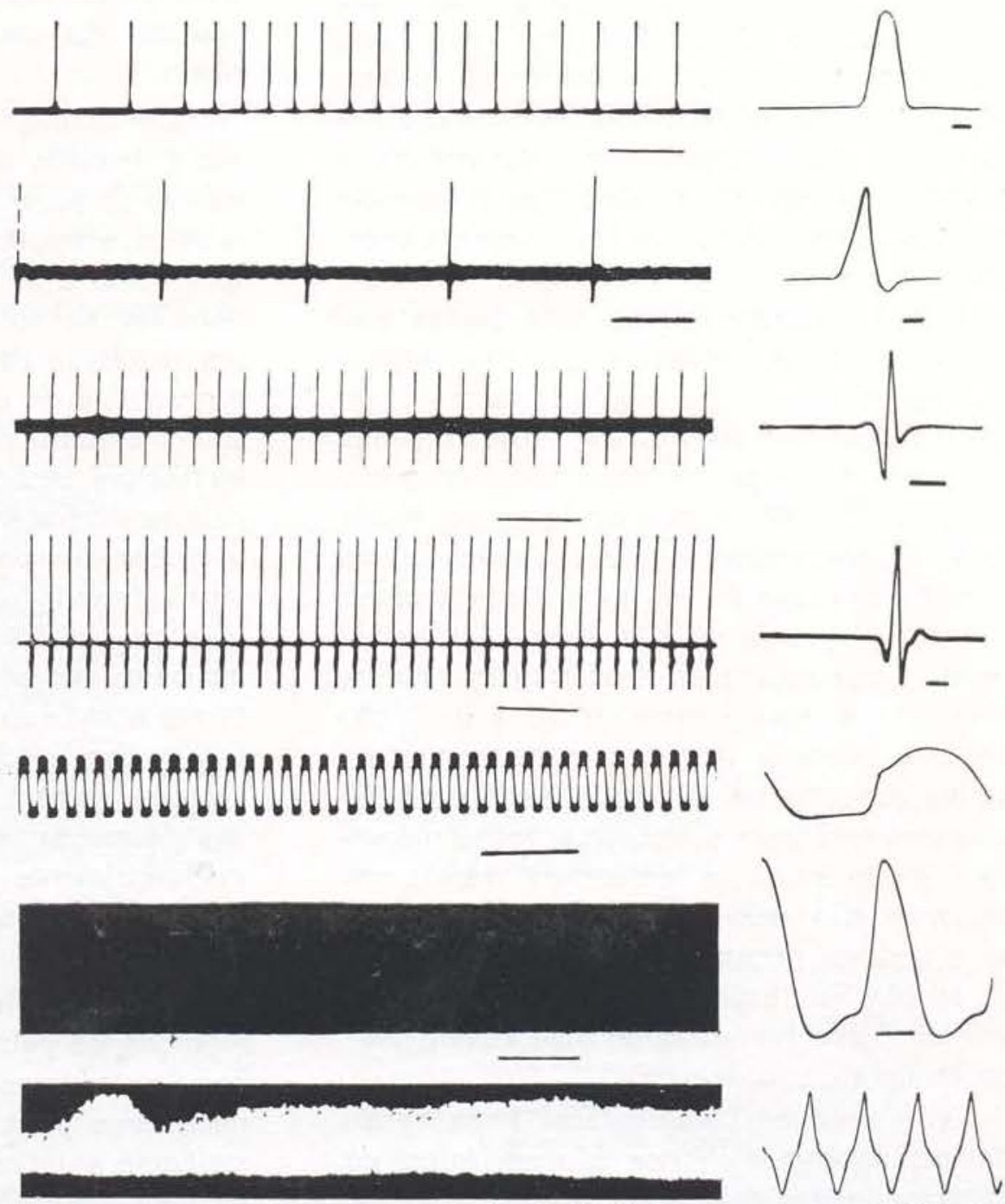

$100 \mathrm{msec}$

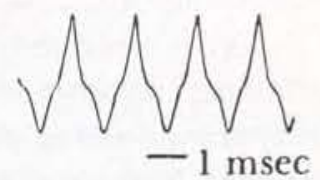

Fig. 4 - Tipos de descargas de órgãos elétricus. São mostrados vários exemplos de gimnotoides dã América do Sul para ilustrar a variedade de taxas de repetição e formas de ondas. As primeiras 4 espécies pertencem so grupo chamado de "espécies pulsadoras", porque o intervalo entre as descargas é relativamente longo. As últimas 3 espécies pertencem ao grupo chamado de "espécies onduladoras", pois o intervalo é aproximadamente igual à duração da descarga. As DOEs são mostradas simultaneamente em escalas de tempo mais lentas ou mais rápidas (de Hagiwara \& Morita, 1963). 
sobre o ambiente numa alta taxa, e as mudanças na freqüência das descargas estão associadas mais estreitamente com comunicação social do que com detecção de objetos.

O órgão elétrico descarrega em resposta a um sinal de comando do sisiema nervoso central. Este sinal origina-se em um núcleo de células localizado na porção do cérebro chamada bulbo e, com exceção do "catfish" elétrico, é transmitido à medula espirhal por outros neurônios. No "catfish" elétrico existem apenas duas células neurais de comando na medula espinhal, e cada uma delas se ramifica profusamente para inervar todos os eletrócitos de cada lado do corpo.

O órgão elétrico descarrega uma vez para cada sinal de comando. Na enguia-elétrica, há exceção, pois uma série de sinais de comando de baixa freqüência produz a descarga elétrica fraca. O desencadeamento de um comando de alta freqüência causa potenciais de junção sub-limiares nos eletrócitos do órgão principal e na parte anterior do órgão de Hunter; estes potenciais imediatamente somam-se para produzir uma descarga de alta voltagem, a qual então segue os sinais de comando na proporção de $1: 1$.

Uma descarga máxima será produzida quando todos os eletrócitos descarregarem simultaneamente. Isto significa que o sinal de comando deve efetivamente chegar aos vários eletrócitos simultaneamente. Existem dois modos principais pelos quais a descarga sincrônica de eletrócitos distribuídos espacialmente pode efetuar-se: a) pelo comprimento constante do caminho neuronal dos núcleos de comando aos eletrócitos, com um caminho direto aos eletrócitos distais a um caminho em circuito aos eletrócitos proximais, e b) pela gradação nos tempos de condução, com uma condução mais rápida do núcleo de comando aos eletrócitos distais do que aos proximais.

$\mathrm{Na}$ enguia-elétrica, a sincronia é efetuada pelos tempos de condução das fibras inervadoras. As fibras que inervam os eletrócitos anteriores (fisicamente mais próximos ao núcleo de comando) possuem menor diâmetro e velocidade de condução mais baixa do que as fibras que inervam os eletrócitos mais poste. riores.
FUnções DA DOE NA VIDA DOS GYMNOTOIDES E OUTROS PEIXES :

COMPORTAMENTO E DOE CORRELACIONADAS

Duas funções principais da DOE no comportamento tem sido demonstradas por meio de experimentos controlados em tanques de laboratório: que denominamos eletrolocação e eletrocomunicação. Cada uma delas representa contribuições muito diferentes para a vida do animal. Espécies diferentes podem enfatizar uma ou outra dessas contribuiçñes, servindo para definir as pressões seletivas que presumimos sejam responsáveis pela diversidade de formas de DOEs.

\section{A. ELETROLOCAÇÃ̃o}

Podemos dist́inguir um modo ativo e outro passivo. Por conveniência, consideraremos conjuntamente a orientação própria do animal em grandes campos elétricos homogêneos e sua localização de objetos ou de pequenas heteroneidades no campo ou na impedância.

$O$ modo ativo pode ser baseado na DCE, cujo campo é distorcido por objetos, ou nos movimentos do peixe em um campo magnético, pelos quais ele induz um campo elétrico detectável por seus eletrorreceptores. O primeiro caso depende de pulsos curtos de corrente e portanto de eletrorreceptores sensíveis aos componentes de alta freqüência. A detecção de corrente induzida é muito menos estudada, mas deve depender dos eletrorreceptores sensiveis às baixas freqüências; posvelmente isto é importante só no mar. Principalmente tubarões e raias são conhecidos serem capazes da detecção de campo magnético.

O modo passivo também pode depender da alta ou da baixa freqüência da DOE ou de fontes de corrente de órgãos não-elétricos. O primeiro caso ocorre quando um peixe elétrico detecta a DOE de outro. O segundo ocorre quando um tubarão, um "catfish" ou um peixe elétrico, utilizando seus receptores de baixa freqüência, detecta a fraca corrente contínua ou o campo elétrico lentamente modulado de um peixe, que é a presa. 
Consideraremos apenas o caso de eletrolocação ativa baseada na distorção do campo de DOE por heterogeneidade de impedância (Fig. 5). Esta notável capacidade dos peixes elétricos, como os gimnotóides, é um ativo sistema sensorial eficiente para centímetros, ou melhor, cerca de um ou dois comprimentos de corpo. Com relação a esta limitação ao campo próximo, ela difere da ecolocação em morcegos, golfinhos e alguns pássaros (assim como pelo fato de que a energia emitida é medida pelos receptores em termos de intensidade local em vários pontos do corpo e não em termos de tempo de retorno, o qual é virtualmente instantâneo). Ainda temos apenas informações insuficientes a respeito da capacidade de eletrolocação em relação à resolução, discriminação da forma etc. É certo que objetos de impedâncias consideravelmente diferentes da impedância da água - e.g. gravetos, podem ser detectados a uma distância de um comprimento de corpo, mesmo que sejam de apenas poucos milímetros de diâmetro. Do mesmo modo, pequenas aberturas numa rocha ou num emaranhado de raízes podem ser detectadas. Objetos maiores podem ser detectados, mesmo que suas impedâncias sejam apenas levemente diferentes da impedância da água. Evidências fisiológicas dos receptores tornam provável que pelo menos o peixe ondulador pode distinguir resistência ohmica de reatância capacitativa. Ainda não está claro como alimentos pequenos, e.g. zooplancton, podem ser localizados pelo sentido elétrico. Parece que a eletrolocação é útil para encontrar alimento, para detectar outro peixe e para evitar obstáculos ou detectar fendas.

A capacidade ativa de eletrolocalizar objetos em seu ambiente e passiva de detectar sinais elétricos fracos, permite ao peixe elétrico, como os gimnotóides, viver em águas de pouca visibilidade, ser mais ativos durante a noite e permanecer escondidos durante o dia. Desta forma, eles minimizam a captação por predadores visuais, como ciclídeos e siluróides

A eletrolocação ativa baseia-se no seguinte princípio. A corrente da descarga do órgão elétrico flui sucessivamente através da pele, da água que circunda o animal e volta através da pele. Os eletrorreceptores estão localizados em poros na superfície do corpo e agem como monitores das intensidades locais do fluxo da corrente transcutânea. Objetos próximos da superfície do corpo do animal intensificarăo ou atenuarão o fluxo da corrente transcutânea local, conforme sua resistividade seja mais baixa ou mais alta do que a da água circundante. Estas mudanças locais nos padrões de fluxo representam a "imagem elétrica" dos objetos. A intensidade e o contraste de tais imagens são uma função da resistência relativa da pele e geometria do corpo. Por exemplo, um longo filamento caudal, típico para muitas espécies de peixe elétrico, amolia a faixa de eletrolocação do animal e o contraste das imagens elétricas é aumentado conforme o animal curve seu corpo e cauda ao redor dos objetos de interesse.

As imagens elétricas são projeções bidimensionais do ambiente sobre a superfície do corpo do animal, o que pode ser então comparado com a retina no domínio da visão. Os eletrorreceptores projetam-se somatotopicamente em camadas nas unidades de ordem mais alta no lobo da linha lateral, torus semicirculares e cerebelo (ver mais abaixo). Interaçōes mútuas entre unidades adjacentes são acionadas para o processamento da imagem elétrica $e$ detecção da forma. Os eletrorreceptores são assim organizados em padrōes de campos receptivos, os quais assemelham-se aos campos receptivos visuais em termos de centros excitatórios, vizinhanças inibidoras, sensibilidade a movimentos unidirecionais etc. Parece que a visão e a eletrolocaçăo desenvolveram princípios semelhantes no processamento de imagens bidimensionais do ambiente.

A eletrolocação assemelha-se à ecolocação no sentido em que o animal avalia seu ambiente por uma retroalimentação continuamente avaliada por suas próprias ações do que por uma exploração passiva de fontes de energia estranhas, como a luz solar. Necessitamos de novas pesquisas sobre os parâmetros usados na eletrolocação em várias espécies, os limites de utilidade em relação, por exemplo, com a forma, tamanho, posição, movimento, contraste da água em condutância ohmica e a presença e geometria da reatância capacitativa. 


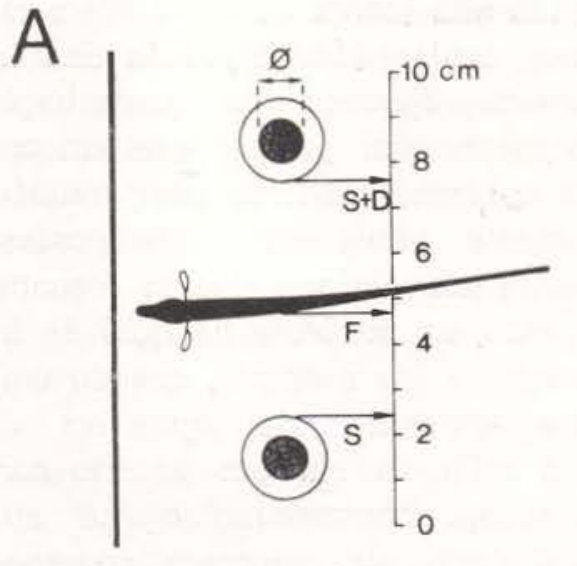

$$
\varnothing=15.6 \mathrm{~mm}
$$

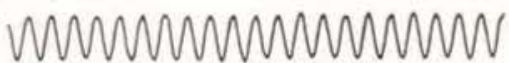
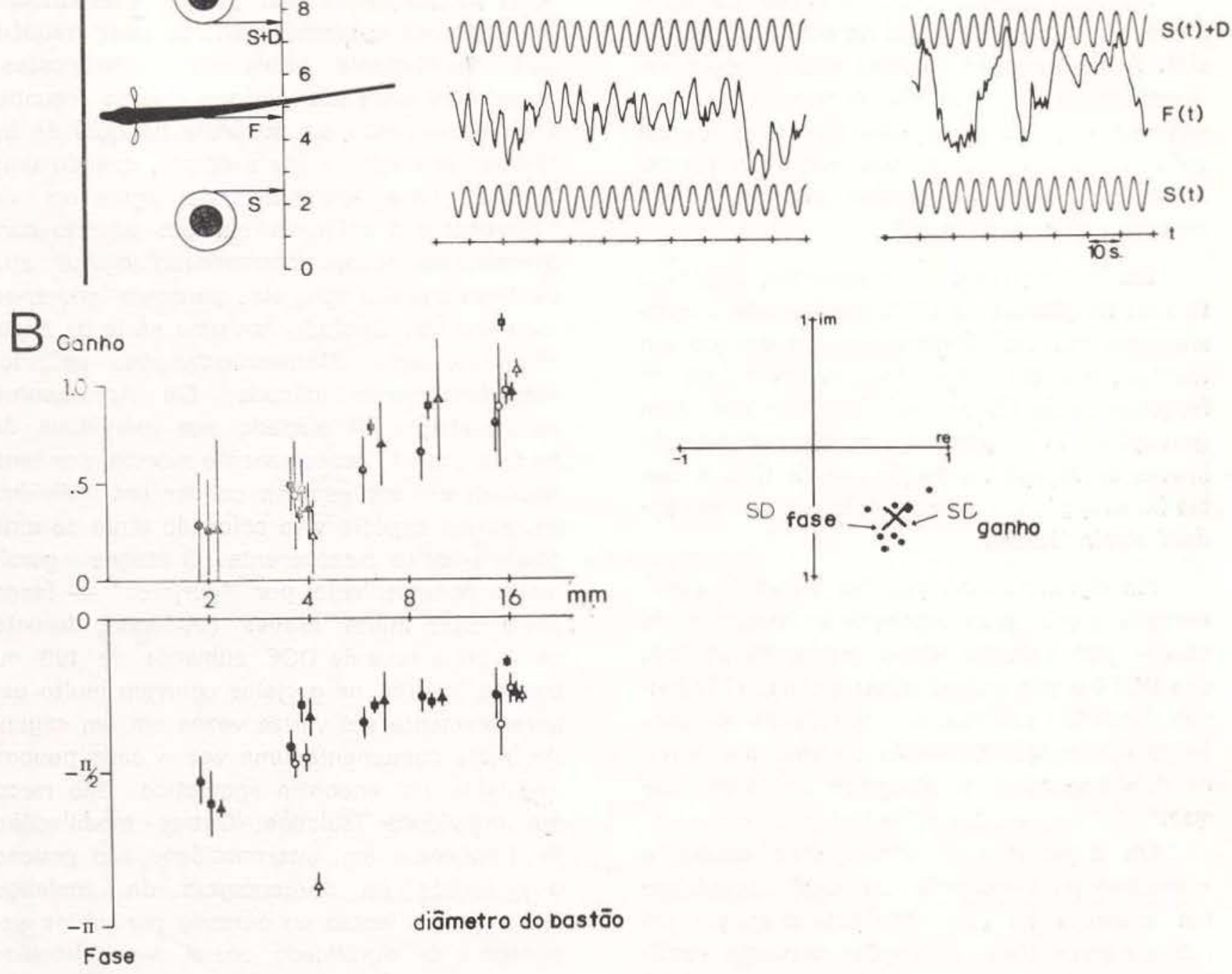

Fig. 5 - Eletrolocação. A. Um peixe elétrico, flutuando entre dois bastōes de plexiglas suspensos verticalmente (secção transversal à esquerda), segue um movimento sinusoidal, $S(t)$ e $S(t)+D$, por translação lateral do corpo $F(t)$. Esta resposta é prejudicada e ocorrem freqüentes colisões quanto menores forem os diâmetros $\phi$ dos bastōes escolhidos. Todos os bastões são escondidos dentro de moldes de agar para cancelar as diferenças nas informações mecânicas. Uma placa vertical de plexiglas em frente ao animal que flutua estabiliza sua posição entre os bastōes oscilantes (diagrama à esquerda). As análises de Fourier da resposta de seguimento do animal; $F$ ( $t$ ). revelam um forte componente na freqũência dos estímulos, $S(t)$, que é de $0,2 \mathrm{~Hz}$ em cada registro. A amplitude deste componente, relativa à amplitude de $S(t)$, é chamada "ganho", sua diferença de fase em relação a fase $S$ ( $t$ ) de "fase" nas últimas figuras (de Heiligenberg, 1974). B. "Ganho" e "fase" da resposta de seguimento de Eigenmannia como uma função do diâmetro do bastão de plexiglas, numa freqüência fixa de oscilação de $0.1 \mathrm{~Hz}$ e distância interna entre os bastōes de $6 \mathrm{~cm}$. O animal flutuou no centro do conjunto oscilante e portanto estava aproximadamente a $3 \mathrm{~cm}$ de cada bastão. Símbolos diferentes representam valores médios para espécimes diferentes, as barras verticais representam desvios-padrões. Vaiores médios e desvios-padrões foram calculados a partir de distribuições bidimensionais de dados originais, representados no plano complexo, com ganho e fase como raio e ângulo, respectivamente (colocados mais acima, à direita). Desvio-padrão do ganho é definido como o desvio na direção radial, o ciesvio-padrão da fase é definido como perpendicular ao último (de Heiligenberg, 1973). 
B. ELETROCOMUNICAÇÃO, INCLUINDO SINAIS ASSOCIADOS COM COMPORTAMENTO AGONÍSTICO

As descargas do órgão elétrico desempenham um importante papel na comunicação social. A identificação do sexo e da espécie freqüentemente baseia-se nas características das descargas típicas da espécie e do sexo e o estado comportamental de um animal freqüentemente se reflete nos modos particulares da atividade elétrica (Fig. 6).

Em Sternopygus, por exemplo, o estado fixo da freqüência de DOE das fêmeas é aproximadamente um oitavo mais alto do que em machos, e estes respondem seletivamente às freqüências da fêmea em experimentos com gravações. A resposta do macho consiste de breves elevações na freqüência de DOE e curtas interrupções, e estes sinais por sua vez podem atrair fêmeas.

Em Gymnotus carapo, um indivíduo dominante assinala suas ameaças e intenções de ataque por característicos aumentos na taxa dos DOEs e por breves interrupções. O indivíduo dominado assinala sua submissão por uma longa interrupção (silêncio elétrico por cerca de dois segundos) e isto pode evitar um ataque.

Em Eigenmannia, interrupções curtas e elevações na freqüência de DOE, assinalam um aumento na prontidão para o ataque em machos territoriais. Elevações graduais seguidas por um lento retorno na freqüência de DOE assinalam um comportamento submisso. Séries de modulações na taxa de DOE acompanham os comportamentos de corte e territorial e podem servir a funções semelhantes à do canto dos pássaros. Sua função comunicativa é evidente pelo fato de que não apenas refletem certos estados comportamentais, mas também provocam respostas específicas em indivíduos da mesma espécie. Eigenmannia, Apteronotus e Sternopygus ignoram-se mutuamente, o que sugere um reconhecimento de espécies.

As espécies onduladores de alta freqüência, os Apteronotidae, têm sido ao menos estudadas etologicamente e merecem atenção especial, parcialmente face ao fato de sua taxa de DOE ser tão alta (cerca de 800-2100) e tão extremamente regular (desvio-padrăo dos intervalos durante épocas sem perturbação $<0,1 \mu \mathrm{s}$ !), mas também porque existem tantas espécies e mesmo gêneros com freqüências fundamentais amplamente sobrepostas. Já existem evidências de que elas se reconhecem mutuamente, na ausência habitual de interação agonística. Por exemplo, quando uma espécie intra-especificamente agressiva de Apteronotus é colocada em um aquário com Sternarchogiton sp., Sternarchorhamphus sp., ou Sternarchella $\mathrm{sp}$., elas parecem ignorar-se mutuamente. Contudo, em uma série de experimentos, uma Sternarchorhynchus sp., foi persistentemente atacada. Em Apteronotus sp., o ataque foi eliciado por indivíduos da mesma espécie recentemente mortos, por uma imagem em um espelho ou por um individuo da mesma espécie vivo colocado atrás de uma chapa plástica transparente. $\mathrm{O}$ ataque - geralmente acompanhado por "gorjeios" - fases transitórias muito breves $(20-50 \mathrm{~ms})$, durante os quais a taxa de DOE aumenta de 100 ou mesmo $200 \mathrm{~Hz}$; os gorjeios ocorrem muito esporadicamente até várias vezes em um segundo, mais comumente uma vez a cada poucos segundos no encontro agonístico. São raros em indivíduos isolados. Outras modulações de freqüência em apteronotídeos são poucas e pequenas na porcentagem de mudança $(1-2 \%)$, mais lentas ou durando por vários segundos e de significado social desconhecido; é mais provável que ocorram quando outros indivíduos da mesma espécie ou suas DOEs estejam presentes, e totalmente improváveis com perturbações mecânicas, alimento ou luz.

As diferenças entre espécies quanto às características espectrais e temporais de DOE e a seletividade associada dos eletrorreceptores às DOEs das espécies, certamente aumentam o reconhecimento e a separação das espécies. Espécies simpáiricas estreitamente relacionadas podem geralmente ser identificadas mais prontamente por suas DOEs do que pelas clássicas características morfológicas. As colorações do corpo servem primeiramente para a camuflagem do animal, não possuem nenhuma função de aviso na comunicação intra-específica e são muito variáveis. As ca- 
racterísticas de $\mathrm{DOE}$, provavelmente como conseqüência de seu papel na comunicação social, apresentam considerável variabilidade entre espécies, mas têm uma constância sur- preendente dentro de cada espécie (Fig. 4). Representam mais do que o canto do grilo como informações seguras para a identificação das espécies.

A

\section{B}
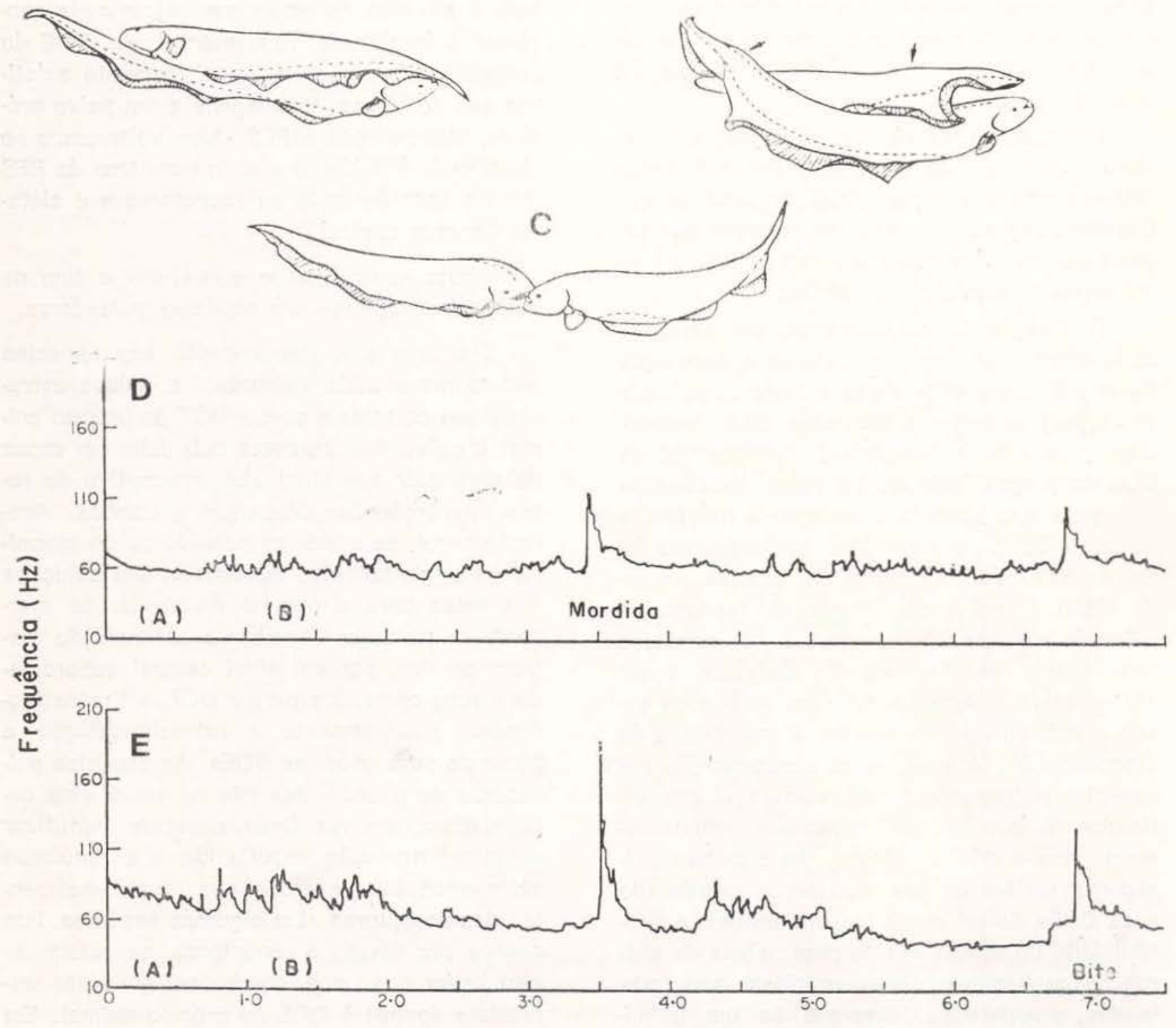

T empo (s)

Fig. 6-Eletrocomunicação. Estão ilustrados une poucos exemplos de modulações de freqüência da DOE de Gymnotus carapo, associadas com o comportamento agonístico. A-C. Alguns padrōes motores agonísticos. A. Disposição latełal antiparalela. B. Serpenteamento mútuo (as setas indicam as curvas dos corpos dos peixes). C. Disposicão frontal mútua. D, E. Atividado elétrica concomitante. D. Freqüência instantânea das DOEs representada contra o tempo. Exibiçōes indicadas para o peixe n.०1 (D) e n.०2 (E). (de Black-Cleworth, 1970). 
C. O PROBLEMA DA INTERFERÊNCIA DE DOES DE PEIXES VIZINHOS; UMA RESPOSTA DE ESQUIVA SALTANDO (RES)

Dois tipos completamente diferentes de interferência com a recepção de sinais podem ser distinguidos: um deles devido a fontes inanimadas de ruído, e.g. relâmpagos (Hopkins, 1973), e fluxos de potenciais (Kalmijn, 1974) e o outro devido a DOEs de peixes vizinhos, especialmente os de outros indivíduos da mesma espécie. Daremos aqui atenção apenas ao problema da interferência de indivíduos da mesma espécie.

Particularmente na eletrolocação, a retroalimentação da DOE do próprio peixe é comumente contaminado pela DOE de outro peixe. Devemos esperar que existam mecanismos específicos que diminuam a interferência de sinal entre transmissores vizinhos.

A atuação da eletrolocação em espécies onduladoras foi medida durante a imposição de interferência controlada e mostrou-se mais vulnerável a sinais sinusoidais com freqüências próximas à frequeência fundamental da DOE do próprio animal. Espécies onduladoras melhoram sua atuação desviando a freqüência de suas DOEs de estímulos de freqüência interferentes. Esta resposta de esquiva saltando (RES) é encontrada apenas na espécie onduladora africana, Gymnarchus, e nas espécies onduladoras da América do Sul, tais como Eigenmannia e Apteronotus: em ambos os casos a RES serve para manter a capacidade de eletrolocação. A atuação da eletrolocação em espécies pulsadoras é mais vulnerável aos estímulos de pulsos que coincidem constantemente com a DOE do animal. As espécies pulsadoras melhoram sua atuação sincronizando suas DOEs de tal modo que minimizam a possibilidade de coincidências com salvas de pulsos desconhecidos. Os mormirídeos africanos tendem a repetir as descargas de um individuo da mesma espécie em intervalos mais curtos do que o intervalo mínimo de DOE esperado de seu vizinho. As espécies pulsadoras da América do Sul, em contraste, disDaram em intervalos mais regulares e deslocam a fase de suas salvas de pulso sempre que coincidências repetidas estejam iminentes.
Considerando que as espécies pulsadoras requerem portanto intervalos de tempo particulares, as espécies onduladoras parecem requerer faixas de freqüência particulares para eletrolocação acurada. Isto não significa tão particular no sentido de que outro peixe não possa detectar uma dada DOE de um peixe ou que um determinadio peixe possa ser seletivamente sensível apenas à sua própria DOE. Como veremos mais adiante, os receptores, embora e afienem de modo que sejam mais sensíveis à freqüência fundamental da DOE do próprio peixe, não são tão nitidamente seletivos que se tornem insensíveis a um peixe próximo, mesmo após a RES. Mas voltaremos ao significado fisiológico e ao mecanismo da RES quando consideramos os receptores e o sistema nervoso central.

Neste ponto, vamos considerar o tipo de RES, primeiramente nas espécies pulsadoras.

Desde que a eletrolocação nas espécies pulsadoras é mais vulnerável a pulsos estranhos que coincidam com a DOE do próprio animal, o peixe elétrico deste tipo deve ser capaz de distinguir seu sinal eletrorreceptivo de retroalimentação das descargas estranhas. Aparentemente, as espécies pulsadoras de mormirídeos e gimnotoides desenvolveram soluções diferentes para o mesmo problema: os mormirídeos parecem escolher a estimulação eletrorreceptiva, por um sinal central subordinado a seus comandos para a DOE, a fim de processar seletivamente a retroalimentação a partir de suas próprias DOEs. As espécies pulsadoras de gimnotóides não possuem esta capacidade e, em vez disso, parecem identificar a retroalimentação escolhendo a estimulação eletrorreceptiva marcada por sinais reaferentes dos receptores. Em algumas espécies, isto parece ser devido a receptores especiais de alto limiar que, sob condiçōes normais, respondem apenas à DOE do próprio animal. Em outros casos, isto pode ser a estrutura habitual do campo da DOE do próprio animal, i.e.. a imagem elétrica habitual do conjunto total de receptores que capacitam o peixe para distinguir sua própria DOE da DOE interferente de um outro peixe. Como os peixes elétricos da África e América do Sul evoluíram separa- 


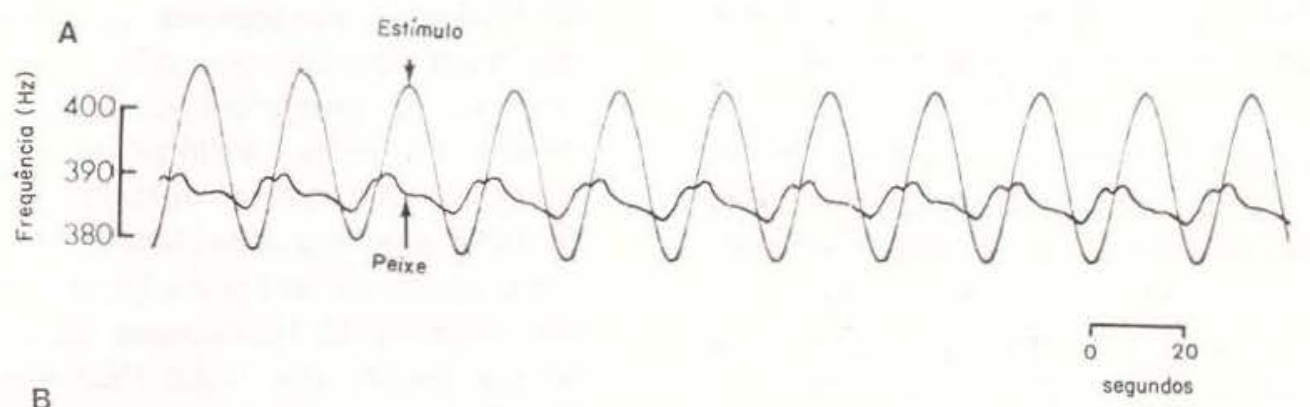

B
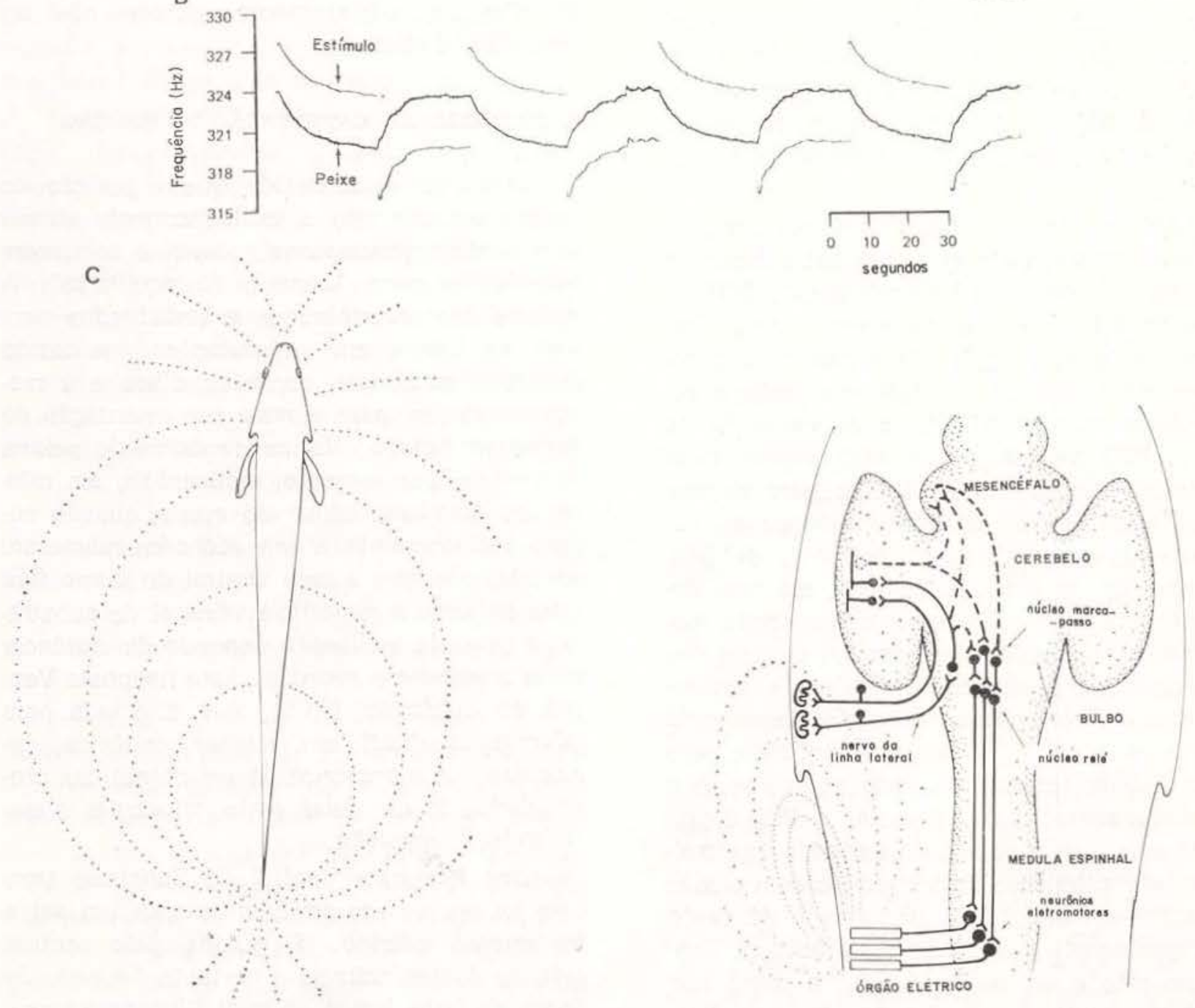

Fig. 7 - A Resposta de Esquiva Saltando (RES) em Eigenmannia. A. Um peixe tentando escapar de estímulo que simula um vizinho, exceto que ele muda sinusoidalmente sua freqüência. Os deslocamentos de esquiva do peixe tâm uma complexa seqüência no tempo dependendo da faixa de variaçāo particular da freqüência do estímulo (aqui cer. ca de $380-408 \mathrm{~Hz}$ ), sua modulaçăo de freqüência (aqui cerca de um ciclo em 20 segundos) e da amplitude e orientação do seu gradiente de voltagem. O estímulo efetivo é provavelmente a diferença de freqüência ( $\triangle F=F$ estímulo $-F$ peixe) e isto está continuamente mudando. B. Um método estudado da RES enquanto se mantém o estimulo $(\triangle F$ constante). Um circuito que corrige automaticamente a diferença de freqüência monitora às mudanças do peixe na freqüência e controla o estímulo para manter uma diferença constante de cerca de $+4 \mathrm{~Hz}$ por 25 segundo, depois $-4 \mathrm{~Hz}$ por 25 segundo e assim por diante. O peixe tenta aumentar a diferença mas não desloca mais do que uns poucos $\mathrm{Hz}$ antes de fixar-se num platô; isto dapende da voltagem e orientação do estímulo., C. Os componentes principais deste comportamento (de Bullock et al., 1972 a, b). 
damente, eles podem ter resolvido vários destes problemas comuns de maneiras diferentes.

Os peixes pulsadores da América do Sul respondem tipicamente à interferência causada pela DOE de um peixe vizinho com uma aceleração ou, menos freqüentemente, uma desaceleração na taxa de repetição dos pulsos. Podem manter uma taxa diferente e assim reduzir a chance de pulsos coincidentes. Apenas uma série de várias coincidências consecutivas é grave em termos de prejuízo na detecção de objetos, e basta manter os pulsos estranhos a poucos milissegundos da coincidência.

Espécies onduladoras enfrentam um problema diferente, visto que toda outra descarga em forma de onda irá interagir com a DOE do peixe para formar um batimento numa freqüência diferente $(\triangle F)$. Para manter a capacidade de eletrolocação, aparentemente é suficiente manter o $\triangle F$ acima de cerca de 10 $\mathrm{Hz}$. A RES nas espécies onduladoras varia desde uma tendência simétrica: para aumentar a freqüência de DOE na presença de um baixo $-\triangle F$ e diminuir a freqüência de $D O E$ na presença de um baixo $+\Delta F$, até uma ênfase assimétrica sobre uma dessas duas mudanças, negligenciando a outra. A maioria dos indivíduos de Eigenmannia tendem a ser simétricos. Apteronotus responde tipicamente apenas ao $-\Delta F$, deslocando a freqüência para cima; depois retorna em resposta ao $+\Delta F$ ou para a remoção do estímulo. A RES é graduada com a intensidade do estímulo (normalmente a proximidade do vizinho) e com o $\Delta F$; é máxima em um $\triangle \mathrm{F}$ de cerca de $4 \mathrm{~Hz}$, tanto em Eigenmannia quanto em Apteronotus. Possui um teto e um mínimo, I.e., o peixe não se afasta muito de sua freqủência normal de DOE; geralmente a alteração máxima é de 5 a $15 \mathrm{~Hz}$. A constante de tempo é lenta; após um rápido início de 0,15-0,2 segundos (o que é täo rápido quanto o reflexo humano de afastamento de um estímulo doloroso), a RES total é atingida apenas após algumas dezenas de segundos. Daí em diante, ela pode ser mantida tonicamente na presença do $\triangle F$. $O$ peixe não fog̃e espacialmente, i.e., move-se para longe da proximidade dos vizinhos em associação com a RES. Algumas espécies são territoriais e espaçam-se mutuamente mesmo que suas frequeências não sejam próximas. Outras são gregárias e permanecem juntas mesmo que suas freqüências sejam muito próximas. Desde que a variação natural da taxa da DOE nas espécies induladoras estende-se sobre várias centenas de $\mathrm{Hz}$, e apenas vizinhos em cerca de $10 \mathrm{~Hz}$ causem uma RES, a maioria dos peixes não induz RES uns nos outros. Sternopygus, curiosamente, parece não ter uma RES distinta.

\section{CONTROLE DA MANUTENÇÃO DA POSIÇÃO}

Está bem estabelecido que a posição de muitos animais não é exclusivamente guiada pelo sentido gravitacional, o qual é comumente referido como "sentido do equilíbrio". A maioria dos invertebrados e vertebrados também se baseia em estimulaçōes em outros sistemas sensoriais, como os olhos e a mecanorrecepção, para ajustar sua orientação do corpo no espaço. Várias espécies de peixes de recifes, por exemplo, inclinam-se, em relação ao eixo-longitudinal do corpo, quando nadam paralelamente a um rochedo submerso, de tal modo que o lado ventral do corpo fica mais próximo à superfície vertical do substrato; o grau de inclinação depende da distância entre o peixe e o rochedo. Esta Resposta Ventral ao Substrato (RVS), que é guiada pela informação visual em muitas espécies, demonstra que a presença de um cbjeto nas proximidades de um peixe pode influenciar o seu controle de posição.

Uma Resposta Ventral do Substrato também foi encontrada em Eigenmannia, um peixe fracamente elétrico. É guiada pelo sentido elétrico destes animais e portanto depende do órgão da linha lateral, o qual filogeneticamente está estreitamente relacionado ao sistema vestibular. Entre outros aspectos sob:e como o sistema eletrossensório é usado como sistema de orientação, é necessário também discutir-se o significado deste sistema para o controle do equilíbrio. O sistema eletrossensório tem a função de ajustar a posição do peixe em relação à orientação espacial dos objetos no habitat do animal. Os seguintes experimentos elucidaram este mecanismo: se um Eigen. mannia que foi cegado flutua a uma distância 
equivalente à altura de um corpo acima de uma placa de plexiglas inclinada de $45 .^{\circ}$, uma resposta de inclinação (rotação) de cerca de $300^{\circ}$ é observada (Fig. 8A). Esta RVS, em relação ao eixo de rotação, é denominada RVSr Substituindo-se a placa de plexiglas isolada (eletricamente visivel) por uma placa de agar, a qual é mais ou menos eletricamente transparente, é provocada uma resposta de inclinação fortemente reduzida (Fig. 8B). Isto demonstra a relevância das informações elétricas para RVS em Eigenmannia.

Além da RVS em relação ao eixo de rotação, outras respostas também ocorrem em relação ac eixo de inclinação (Fig. $8 \mathrm{C}$ e D). Se o peixe estiver orientado com seu plano sagital na vertical e perpendicular à placa de plexiglas de $45 .^{\circ}$, observa-se uma VSR no plano vertical. Se o peixe estiver flutuando acima da placa, com a cabeça voltada para ela, isso resulta numa resposta de inclinação para cima (RVSc). As medidas dos desvios da cabeça e cauda da horizontal são muito diferentes (Fig. 8C). Quando orientado na direção contrária à placa, o peixe exibe uma resposta de inclinação para baixo (RVSb). Neste caso, os ajustes da cabeça e causa são semelhantes (Fig. 8D). Novamente os desvios da horizontal são muito menores com uma placa de agar. mais ou menos transparente eletricamente.

Estas observações demonstraram que a posição de flutuação de Eigenmannia depende da orientação do fundo ou do objeto que está próximo ao peixe. Contudo permanece obscuro o porque destes animais terem desenvolvido um tal mecanismo de controle de posição. É provável que as observações no campo possam esclarecer um pouco mais a respeito do significado deste padrão de comportamento para Eigenmannia em seu habitat normal. Tem sido sugerido que a RVS de certos peixes de recife, guiada visualmente, facilitaria a camuflagem e a obtenção de alimento do substrato. Possivelmente vantagens do mesmo tipo resultam deste comportamento em Eigenmannia.

\section{E. RÍTMOS CIRCADIANOS: PERÍODOS ATIVOS "VERSUS" PERÍODOS INATIVOS}

Observações gerais na natureza corroboraram a asserção de que a atividade locomoto- ra e freqüência de DOE dos gimnotóides em geral são maiores, durante a noite e menores durante o dia. Esta característica é adaptativa para a sobrevivência, em relação aos predadores que não possuem sentidos especiais para a orientação e captura de pressas notur.

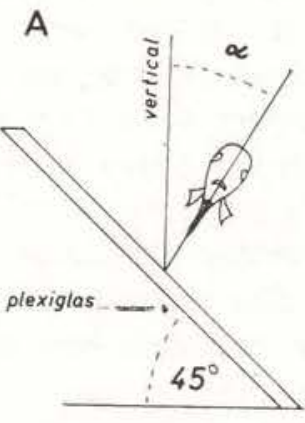

RVSr: $\propto=30^{\circ}$

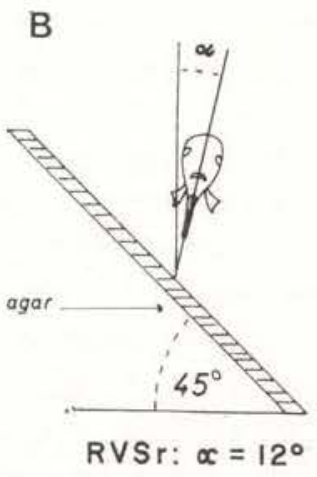

D

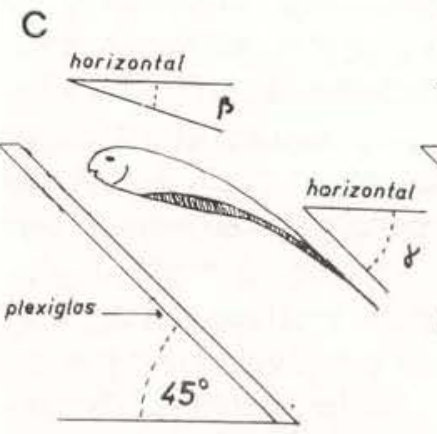

RVSc: $\beta=8^{\circ}$

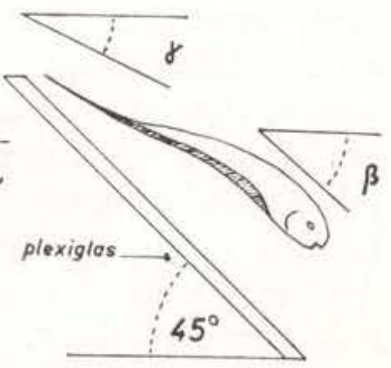

RVS b: $\beta=44^{\circ}$
Fig. 8-A Resposta Ventral ao Substrato (RVS). Eigenmannia virescens mostra mudanças de posição em resposta a objetos no ambiente. Este comportamento garante uma orientação do ccrpo na qual o lado ventral do mesmo fica mais próximo ao substrato quando o peixe nada perto dele. A RVS é guiada pelo sentido elétrico e assim permanece após a cegueira. Os dados seguintes foram obtidos destes espécimes. A) Enquanto flutua acima de uma placa de plexiglas inclinado de 45. ${ }^{\circ}$ um Engenmannia cego exibe uma inclinação média de $300^{\circ}(\propto)$ em relação aa eixo de rotação (RVSr). B) Esta resposta de inclinação é fortemente reduzida se a placa de plexiglas é substituída por uma placa de agar mais ou menos transparente eletricamente. As RVSs em relação ao eixo de inclinação (C inclinação para cima; D inclinação para baixo) são mostradas na parte inferior da figura. As medidas foram tomadas para a posição da cabeça $(\beta)$ e da cauda $(\propto)$ tanto na situação de inclinação para cima (RVSc) quanto na de inclinação para baixo (RVSb). Os dados numéricos foram baseados em 8 espécimes (de Meyer, original). 
nas. Assim, alguns desses predadores são encontrados sobre o fundo durante esse período. Hypopomus artedi, Eigenmannia virescens, Sternopygus macrurus e Gymnotus carapo escondem-se durante o dia entre a vegetação das margens, no fundo arenoso ou lodoso ou em manchas de vegetação como cabomba, pístia, lírios aquáticos, vitória-régia etc. No crépusculo vespertino, as duas últimas espécies de peixes saem mais pontualmente para água aberta. Sua volta à margem é verificada na manhã seguinte. Eigenmannia chega mais cedo ou mais tarde, logo após o nascer do sol, dependendo do local, e Gymnotus carapo um pouco antes do nascer do dia. Staetogenes elegans tem uma atividade natatória que é melhor sincronizada pela iluminação: assim, sob iuz artificial, ele fica deitado de lado sobre o fundo, como uma folha morta, e sob condições de escuridão, ele nada ativamente. O rítmo da DOE de Sternopygus macrurus apresenta aumentos transitórios durante a noite. As atividades de DOEs de alguns gimnotóides mudam durante à noite como pode ser vistas na Tabela 1. A sobreposição de freqüências interespecifica pode ocorrer durante o dia, quando os peixes estão inativos, visto que, durante a noite, é mais provável que seus rítmos possam diferir. Assim, embora Gymnorhamphichthys hypostomus e Hypopomus artedi tenham freqüências semelhantes, durante o dia, elas diferem à noite; a do $H$. artedi aumenta de 2 a 3 vezes, e a do G. hypostomus de 6 a 7 vezes. $R$. rostratus aumenta sua treqüência de DOE, sua atividade de nado e o tempo que passa na posição vertical com a nadadeira ventral em contato com o fundo durante a noite.

Gymnorhamphichthys possui o mais acentuado contraste entre atividade diurna e noturna de todos os peixes elétricos até agora estudados. Durante o dia, ele permanece completamente enterrado no fundo de areia grossa de igarapés claros, imóvel e descarregando seu órgão elétrico numa baixa taxa (10-15 por segundo). Emergindo muito abruptadamente uns 25-40 min, após o pôr-do-sol, a freqüência de DOE eleva-se instantaneamente a um nivel alto (70-120"por segundo), mantido durante o período ativo. Este, normalmente, teımina quando o peixe repentinamente se enterra na areia, tipicamente entre $03 \mathrm{~h} 20 \mathrm{~min}$ e $05 \mathrm{~h} 00 \mathrm{~min}$. Esta é a única espécie de peixe elétrico que demcnstrou sustentar um rítmo circadiano sob condições estáveis e luminosidade fraca constante. O periodo é então próximo, mas não exatamente, de 24 horas e varia com nível de luminosidade. Num ciclo natural de luminosidade diurna-noturna ele é de exatamente 24 horas.

TABELA 1 - Gimnotóides encontrados na regiăo de Manaus, Amazonas, e stia taxa de repetição de descarga do órgão elétrico (DOE). As espécies são grupadas de acordo com a forma de onda da descarga como ou "espécies pulsadoras" ou "espécies onduiadoras" (Ver capítulo V para definições). Medidas feitas por W. Heiligenberg and J. Bastian em Novembro, 1976, senão estiver especificado. Identificaçōes supostas.

\section{ESPECIES PULSADORAS}

Espécie

Taxa de repetição da DOE $\mathrm{Hz}(25-27 \% \mathrm{C})$

Em águas negras do sistema do rio Negro, Anavilhanas, Taruma Grande, Taruma Mirim, Cuieiras. pH. 4-5, resistividade $100-150 \mathrm{kj} \mathrm{cm}$.

\begin{tabular}{|c|c|}
\hline 1. Hypopomus sp. 1a & $11-$ \\
\hline 2. Hypopumus sp. 2 & $30-$ \\
\hline 3. Hypopumus sp. 3 & $27-$ \\
\hline 4. Hypopomus sp. 4 & $3-$ \\
\hline 5. Hypopomus sp. 5 & $66-$ \\
\hline 6. Hypopygus sp. b & $46-$ \\
\hline
\end{tabular}

Em águas claras do lago Januacá e Rio Solimões. $\mathrm{pH} 7$, resistividade $12-13 \mathrm{~km} \mathrm{~cm}$.

$\begin{array}{llr}\text { 7. Hypopomus sp. } 9 \mathrm{c} & 30-60 \\ \text { 8. Steatogenys elegans d } & 50-60 \\ \text { 9. Rhamphichthys rostratuse } & 40-100\end{array}$

Em águas negras do rio Negro próximas à confluên. cia do rio Branco; captado sobre fundo arenoso a $7-20 \mathrm{~m}$ de profundidade, rochas submersas dispersas; vegetação no fundo esparsa. Muitas amostras colhidas em março-maio, 1967 examinadas no barco de pesquisas Scripps ALPHA HELIX por A. B. Steinbach, M. V. L. Bennett, T. Szabo e T. H. Bullock.

\begin{tabular}{ll}
\hline 10. Gymnohamphichthys sp. $f$ & $25-35$ \\
11. Gymnotus carapo & $45-60$ \\
Também \# 8 e 9 acima. & \\
\hline
\end{tabular}




\section{ESPÉCIES ONDULADORAS}

Em águas claras do rio Solimōes, $\mathrm{pH} 7$, resistivida. de $12-13 \mathrm{kn} \mathrm{cm}$.
12. Sternopygus macrurus
$60-150$
13. Eigenmannia macrops
$430-660$
14. Eigenmannia sp. 1
$580-1000$
possivelmente E. troscheli
ou Rhabdolichops sp.
15. Eigenmannia $\mathrm{sp} .2$
(focinho pontudo)
16. Adontosternarchus sp $1 \quad 950-1250$ (corpo manchado)
17. Adontosternarchus sp $2 \quad 710-1330$ (corpo uniformemente cin- za escuro)
18. Apteronotus anas
19. Sternarchella $\mathrm{sp}$.
$1080-1250$
20. Sternarchorhynchus oxyrhynchus
21. Porotergus sp.
22. Sternarchorhamphus mülleri
$1080-1170$
$1400-1800$
(năo foi gravada)
$740-973$

Em águas negras do rio Negro próximo a confluência do rio Branco (Ver acima).

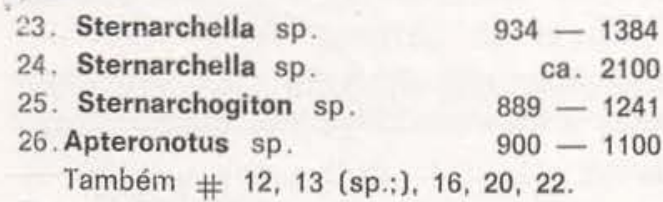

a) Substrato do fundo de lama fofa e folhedo; animais isolados ou em pares; separados de $1 \mathrm{~m}$ ou mais. Todas 5 espécies em comunicação cruza. da, muitas vezes distribuidos diferentemente.

b) $\mathrm{O}$ mesmo que acima, com preferência para o fo. Ihedo e raizame denso; gregário, simpático com espécies acima.

c) Substrato lamaçoso de margens com gramíneas inundadas, animais isolados.

d) Margens com gramineas inundadas, animais isolados.

e) Margens com gramíneas inundadas, próximo ao fundo, animais isolados ou em pares.

f) Esssa é uma freqüência "perturbada e diurna". Valores maiș normais diurnos são $10-15$, à noite 65-100 (Lissmann \& Schwassmann, 1965).

\section{ELETRORRECEPÇÃo}

Experimentos inequívocos na discriminação comportamental que podem ser realizadas só pela detecção de distorção do campo elétrico (Lissmann, 1958) predizeram a existência de eletrorreceptores. Orgãos de sentido especiais para essa nova modalidade foram realmente encontrados e provados fisiologicamente no sistema da linha lateral de peixes gimnotóides, mormiróides e de elasmobrânquios. Um apanhado da descoberta e prova da função destes receptores é dada por Bullock (1974) e resumos mais detalhados de sua anatomia, fisiologia e funções comportamentais são dados em Fessard (1974).

Em resumo, estes órgãos são considerados como derivados especializados do sistema de receptores da linha lateral, que normalmente respondem a correntes elétricas. Essas correntes podem ser ou da própria DOE do peixe ou de outras fontes animadas ou inanimadas. Eletrorreceptores existem não só nos grupos mencionados acima, como também nos siluróides, braquipterígeos (Polyodon, o "spoon bill" e Scaphirhynchus, o esturjão) e provavelmente em alguns outros grupos.

Existem duas grandes classes e várias subclasses destes órgãos de sentido. As grandes classes de eletrorreceptores são (a) bulbosos ou sensiveis à baixa freqüência e (b) tuberosos ou sensiveis à alta freqüência (Fig. 9). Os primeiros existem em todos os grupos de peixes já citados, os últimos ocorrem apenas nos teleósteos elétricos, i.e., aqueles com órgãos elétricos.

Os receptores buibosos são os mais sensíveis, especialmente os das espécies marinhas, onde o forte curto-circuito da água de alta condutibilidade torna o sinal fraco. São usados primariamente para detectar corrente contínua ou as lentas mudanças nos campos elétricos da presa (Fig. 10) e das fontes inanimadas. Uma destas é a corrente induzıda pelo movimento das massas de água, como as correntes marinhas, através do campo magnético da terra, (Kalmijn, 1974). Estes receptores são os mais sensiveis às correntes olétricas, variando um equivalente a cerca de 1-10 $\mathrm{Hz}$, dependendo da espécie. 


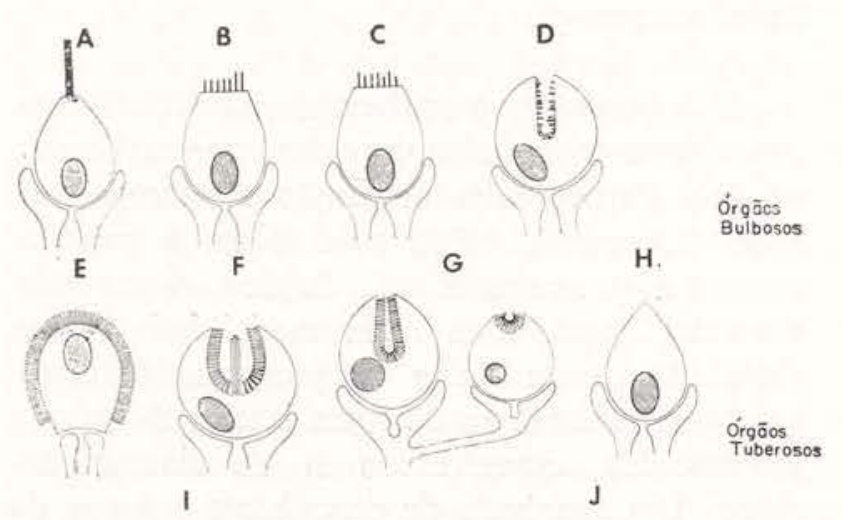

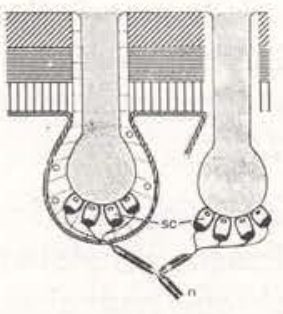

Órgão Bulboso

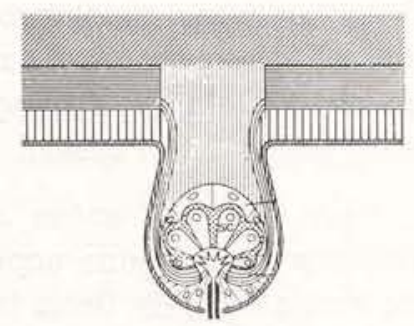

Órgäo Tubaroso
Fig. 9 - Eletrorreceptores. Representações esquemáticas de vários tipos de receptores bulbosos e tuberosos. A-H, as células ciliares modificadas ou células sensoriais secundárias, que se crê sejam as atuais células sensociais. I, J, órgãos do sentido inteiros mostrando a disposição das células sensoriais e sua iner. vação. A, ampola de Lorenzini dos elasmobrânquios: B.D, órgâos bulbosos dos teleósteos, incluindo gimnotoides; $E$, um tipo especial de órgão tuberoso em Mor. myridae chamado "mormyrimast" sc2; F, um órgão em Gymnarchidae chamado "gymnarchomast" II; C, "gym. narchomast" I; H, "mormyromast" sc1; I, órgão bulbo. so em gimnotóide; J, órgão tuberoso em gimnotóide. $\mathrm{n}$, terminação nervosa mielinada (terminaçōes nervosas em I, pretas, $\in \mathrm{m}$ J, brancas); sc, células sensoriais; camadas de pele indicadas por tipos diferentes de pontilhados (de Szabo, 1974).

Os receptores tuberosos são de pelo menos 3 ou 4 subclasses, baseando-se no modo pelo qual eles codificam as diferenças de intensidade. Provavelmente alguns são primariamente detectores da DOE do próprio peixe, outros são usados primariamente na eletrocomunicação - detectando as DOEs de outros membros da mesma espécie. Os receptores tuberosos são os mais sensiveis às flutuações das correntes elétricas de cerca de 100-1.000 $\mathrm{Hz}$, dependendo da espécie e mesmo do indivíduo.
Em espécies onduladoras como Eigenmannia (DOE de cerca de $300 \mathrm{~Hz}$ ), cada peixe tem sua própria freqüência de DOE normaìmente preferida, dentro da variação da espécie, que pode ser $200 \mathrm{~Hz}$ ou mais. Os receptores de um determinado peixe são mais sensiveis às freqüências próximas a sua própria taxa de

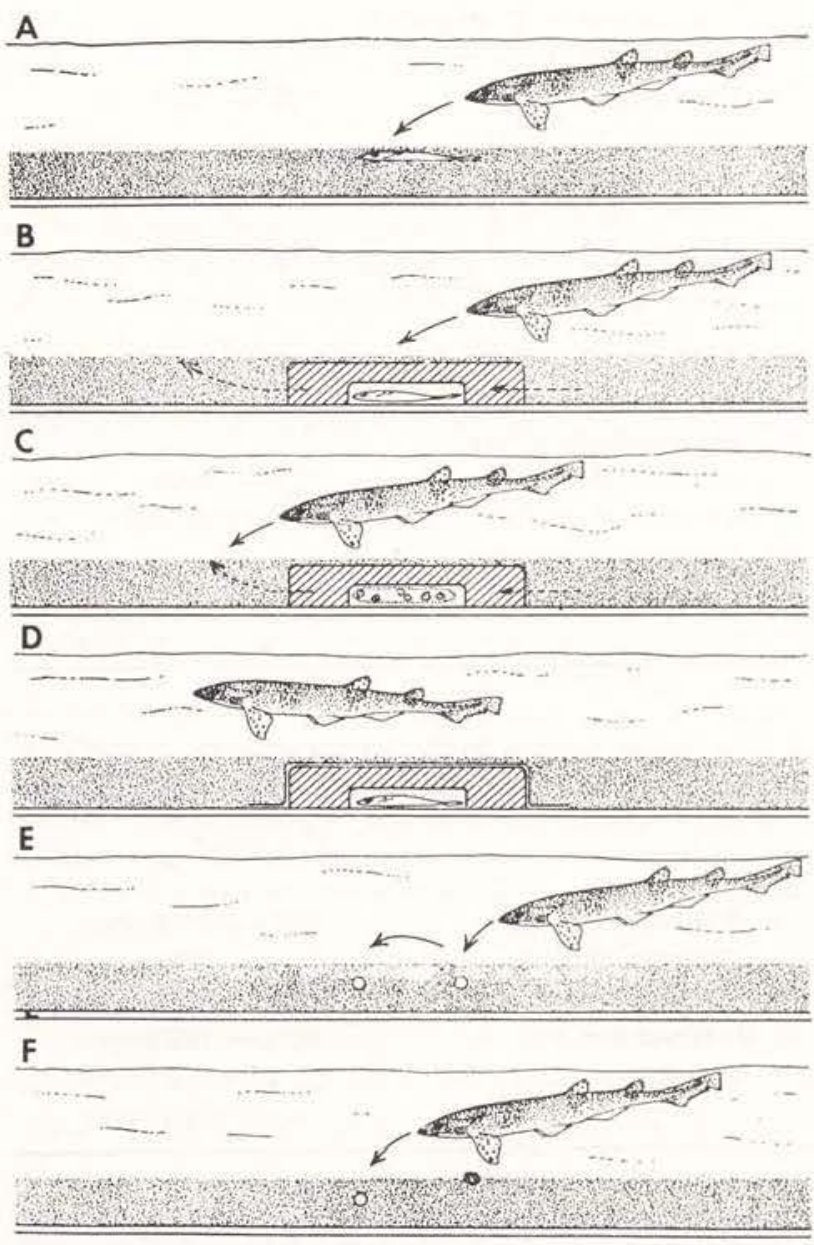

Fig. 10 - Uso da eletrorrecepção por um elasmobrânquio. Experimentos com um tubarão. Scyliorhimus canicula. mostram que a resposta ao alimento pode ser guiado por correntes elétricas fracas, de freqüência muito baixa (cerca de $1 \mathrm{~Hz}$ ) de um peixe presa (o "flatfish". (Pleuronectes plateessa) ou de eletródios na areia (a) o mergulho normal, acuradamente dirigido a um "flatfish" enterrado na areia. b) disto persiste mesmo se o peixe for coberto por uma capa de agar eletricamente transparente. (c) o odor, quando exagerado pelo retalhamento da presa, leva a buscas não direcionadas rio abaixo (d) um filme plástico, eletricamente opaco, impede a resposta. (e) eletródios que simulam o campo bioelétrico de baixa freqüência de um "flatfish" são atrativos. (f) eietródios (apenas um é mostrado) são localmente mais atraentes do que um pedaço de peixe (de Kalmijn, 1971). 
DOE. A sensibilidade oscila tanto acima quanto abaixo desta "meihor frequeência", i.e., os receptores são sintonizados, como filtros passa-banda.

O cérebro desenvolveu sistemas receptores e processadores especializados para a estimulação maciça dos numerosos receptores. Estes são modificações dos antigos centros da linha lateral. Incluem estruturas nos loios da linha lateral no bulbo, no cerebelo e no torus semicirculares do mesencéfalo. Estas estruturas são extremamente grandes e altamente diferenciadas nos peixes gimnotoides e mormiriformes. As vias dos eletrorreceptores também se projetam no telencéfalo. O cerebelo é excepcionalmente grande, não apenas nos peixes elétricos, mas também nos elasmobrânquios, em gerai, e em muitos siluróides. Existe uma certa evidência de que isto esteja em conexấo com a eletrorrecepção, mas as informaçōes são ainda insuficientes.

Muitos neurônios altamente especializados existem nos lobos da linha lateral, no torus semicirculares e no cerebelo dos gimnotóides e respondem aos sinais, derivados de correntes elétricas e possuidores de padrões altamente específicos. Por exemplo, um tipo de neurônio apenas responde à presença de um outro peixe elétrico da mesma espécie. com uma taxa do DOE que seja ligeiramente maior - não muito - do que a taxa de $\mathrm{DOE}$ do próprio peixe (Fig. 11). No cerebelo, certos neurônios respondem apenas quando a estimulação eletrorreceptiva vem de um objeto que esteja se movendo em uma certa direção na água próxima ao peixe. Assim, parece que eletrolocação e a eletrocomunicação sejam servidas por sistemas distintos de analisadores centrais que são responsáveis por aspectos diferentes da estimulação do conjunto de recepiores na pele.

Finalmente é suposto que o sistema da linha lateral tenha evoluído, entre seus resultantes especializados, uma parte na cóclea dos vertebrados superiores. Assim, a pesquisa de eletrorrecepção oferece uma oportunidade especial para desenvolver uma abordagem comparativa ao estudo de nosso próprio ouvido interno, incluindo o órgão auditivo. É impressionante que a sintonia das fibras dos nervos aferentes dos eletrorreceptores tuberosos em
Eigenmannia é tão seletiva como a das fibras do nervo coclear de mamíferos que têm a mesma freqüência ótima, embora a sintonia deste seja considerada derivada principalmente das propriedades mecânicas do ouvido.

\section{PossíveIS SIGNIFICADOS ECOLÓGICO E PRÁTICO}

Grandes oportunidades existem para a compreensão fundamental a respeito da biologia dos gimnotóides e outro peixe eietrorreceptivo. Enquanto cada um dos capitulos anteriores apresenta importantes questões não resolvidas, à espera de novos trabalhos, talvez o tópico mais oportuno e aberto seja a biologia de campo de espécies individuais e o papel dos gimnotóides na comunidade.

A julgar pelas amostras coletadas no Amazonas, utilizando métodos que capturam todos os peixes em várias dezenas de metros cúbi$\cos$ de água, membros de grupo podem freqüentemente dominar a ictiofauna. Parece provável que os gimnotóides sejam a principal fonte de alimento para os grandes predadores. Isto merece um estudo quantitativo. Se somarmos os siluróides eletrorreceptivos, embora não elétricos, abrangendo pelo menos 9 familias diversificadas na América do Sul e que representam uns $40 \%$ da relação das espécies. esta idéia parece importante na ecologia total.

Um significado prático é que deve valer a pena utilizar-se estes peixes como marcadores. Desde que a DOE é contínua noite e dia, (mas com paradas de poucos segundos como sinais em encontros agonísticos), estes animais oferecem uma oportunidade única. Um amplificador iransistorizado portátil $€$ um par de fios em um bastăo permitem que se diga, com um alto grau de segurança, se existe gimnotóides (ou na África, mormirídeos ou gimnarquídeos) em um certo volume de água - sem a necessidade de capturar ou mesmo ver o peixe. Pode fazer-se um censo, realizando-se um trajeto numa profundidade escolnida. A ausência de ruídos ou zumbidos é uma evidência fortemente positiva da ausência de qualquer membro desta superfamília. A eficiência desta técnica é acompanhada pela limitação devida ao rápido declínio na amplitude do campo elétrico com distância num condutor de volume. Na prática, pode geralmente 
detectar-se qualquer gimnotóide numa distância de meio metro (um pouco menos para Sternopygus j, usando-se um aparelho de um único canal e eletródios separados por poucos centímetros. Uma rede de eletródios pode ser conveniente para fins especiais. Uma limitação inerente é que, sem coleta de amostras, existe geralmente alguma ambigüidade nas espécies e mesmo gêneros. Seis ou sete tipos de DOE podem freqüentemente ser distinguidos no campo, pelo ouvido (simplesmente amplificando e convertendo as descargas em sons), ao passo que mais de 12 ou 15 espécies de gimnotóides podem ser, às vezes, coletadas num espaço de poucos metros.

Em várias espécies, foram registrados movimentos, e.g. migração diurna de água rasa entre plantas, para a água aberta longe da margem em um grande rio, o rio Negro. Maiores movimentos com a inundação sazonal da floresta e eventual diminuição do nível da água (de mais de 10 metros) e retração dos habitats aquáticos, podem ser acompanhados pela amostragem de DOEs, talvez mais fácil

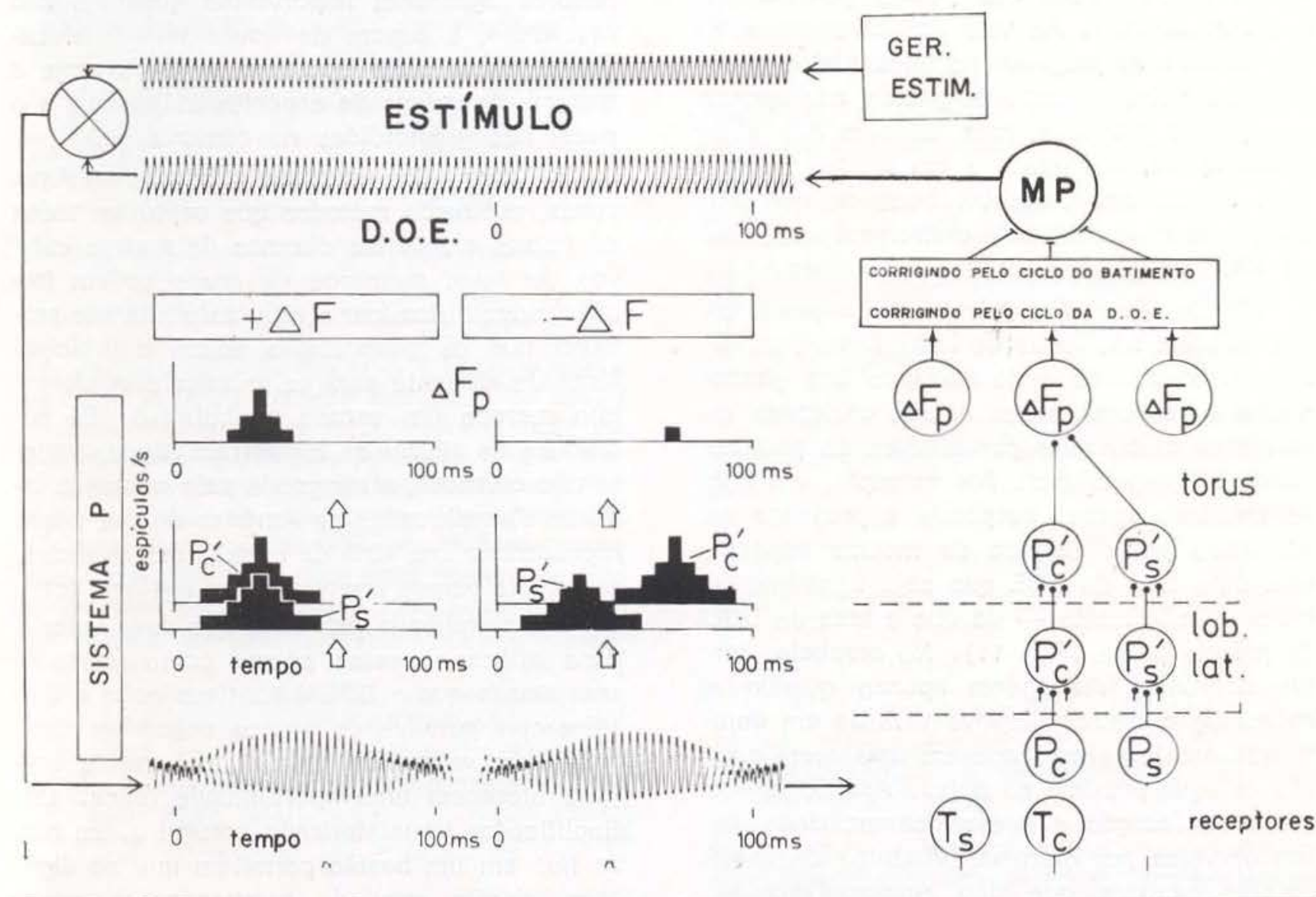

Fig. 11 - Processamento nervoso central da estimulação do eletrorreceptor. O diagrama mostra os componentes de um esquema dos passos sucessivos na Resposta de Esquiva Saltando (RES) em Eigenmannia. A descarga do órgão elétrico (DOE) é comandada pelo núcleo marca-passo (MP) fisiologicamente uma única unidale. O estímulo inicia a descarga de um vizinho. Eigenmannia de uma freqüência ligeiramente diferente, causancio batimentos. Es. tas são de forma assimétrica porque a DOE não é sinusoidal; esta assimetria é essencial para a capácidade dos neurônios de distinguir corretamente entre $+\Delta F$ e $-\Delta F$, i.e. se a frequeência do vizinho é mais alta ou maỉs baixa $e$ portanto a RES devo aumentar ou baixar. Os pequenos círculos representam tipos de neurônios geralmente encontrados nos niveis do sistema nervoso indicado (lob. lat. - lobus lateralis do bulbo; torus = torus semicircularis do mesencéfalo). Outros tipos estão sem dúvida envolvidos também e a figura mostra apenas uma metade do es. quema. As fibras aferentes periféricas do tipo P têm uma maior probabilidade de disparar uma vez cada ciclo de DOE numa certa parte do ciclo de batimento. Esta parte é diferente para $+\Delta F$ e $-\Delta F$ em uma subclassu, as unidades $\mathrm{P}_{\mathrm{c}}$, mas não é diferente $\mathrm{em}$ outra subclasse, as unidades $\mathrm{P}_{\mathrm{s}^{\prime}}$ como mostrado no histogramn de sus taxa de descarga. A convergência destos no torus explica a capacidade das unidades $\Delta F_{p}$ de assinalar $o$ sinal do $\Delta F$ e contrclar a direção de deslocamento de MP. (de Scheich \& Bullock, 1974). 
ou extensamente do que por métodos tradicionais. Tanto os movimentos microgeográficos - até centímetros, quanto a distribuição macrogeográfica apresentam oportunidades de solução pela amostragem da população elétrica. Parece pcssível que conjuntos particulares de espécies, incluindo plantas e peixes maiores, possam viver juntos, mas podem não ser constatáveis sem amostragem por captura. O conjunto de gimnotóides pode ser marcador para a grande comunidade; eles podem ser reconhecidos por amostragem eletrônica, mesmo que alguma ambiguidade relativa as espécies possa permanecer no campo.

Os numerosos gêneros e espécies de gimnotóides, sem dúvida, incluem generalistas e especialistas, e.g. em hábitos alimentares, em exigências ecológicas e biologia da reprodução. Em vista das razões já mencionadas para o valor especial da melhor compreensão deste grupo, é altamente desejável aprenaerse mais sobre as características destas espécies, em estudo correlacionado de campo e laboratório. Alguns passos já foram dados com a bem sucedida reprodução de Eigenmannia viresnces em laboratório (Kirschbaum, 1975), com a análise de conteúdo estomacal de uns poucos gimnotóides (Knöppel, 1970) e com os minuciosos estudos de campo de algumas poucas espécies (Hopkins, 1974 a,b,c; Schwassmann, 1971; Heiligenberg \& Bastian, 1977 e Hopkins \& Heiligenberg, 1977).

No que concerne ao grande subgrupo de peixes eletrorreceptivos que não são elétricos, o significado ecológico deve ser enorme. Empregando apenas receptores sensíveis à baixa frequiência, tanto quanto sabemos, eles operam principalmente de modo passivo, detectando fontes de correntes estranhas, como a presa. Outras fontes podem ser normalmente importantes, incluindo o próprio corpo do peixe receptor. Estamos falando aqui de vários grupos não relacionados, alguns ainda incertos, mas principalmente de alasmobrânquios e siluróides.

$\mathrm{Na}$ América do Sul, a raia de água doce é localmente abundante e uma grande praga para pescadores e banhistas. Ocorrência de váriós tubarões eurihalinos são ocasionais em pescarias. De muito maior importância, contudo, é o grande grupo dos siluroides, por seu vasto número tanto de espécies quanto de indivíduos. Muitas espécies comercialmente importantes são siluroides.

As oportunidades para pesquisas desses grupos são certamente muito diferentes daquelas de grupos que possuem descarga de órgão elétrico. Os estudos referentes ao papel da eletrorrecepção na etologia de alguns dos diversos "catfishes" são importantes para a compreensão do seu significado ecológico.

\section{AgradeCIMENTOS}

A colaboração dos autores neste trabalho foi ajudada pelo Conselho Nacional do Desenvolvimento Científico e Tecnológico (CNPq), a Universidade Federal de Minas Gerais, a Deutsche Forschungsgemeinschaft, a Technische Hochschule, Darmstadt, a Universidade de Göttingen, a Universidade da Califórnia, San Diego, à Fundação Nacional de Ciências e o Instituto Nacional de Saúde, E.U.A.. Os autores expressam seu agradecimento especial ao Dr. Warwick Kerr e ao pessoal do Instituto Nacional de Pesquisas da Amazônia, Manaus, especialmente aqueles do Departamento de Ictiologia, pela hospitalidade extremamente proveitosa.

\section{SUMmary}

An overview of the families, genera and some species of the Gymnotoidei is presented with a review of their behaviour and natural history. Characteristics of the electric organs and electric organ discharge (EOD) for various species are presented. The role of EOD on the animal's life is discussed, especially as it relates to behaviour and other events. Electroreception, its special sense organs and brain-processing, including use by non-electric fish is discussed. The results of these studies are interpreted in terms of their pratical and ecological significance in the life of this group of fish.

\section{BIBLIOGRAFIA}

Altamirano, M.; Coates, C.W.; Grundfest, H. \& NACHMANSOHN, D.

1953 - Mechanisms of bioelectric activity in electric tissue. 1. The response to indirect and direct stimulation of electroplax of Electrophorus eletricus. J. Gen. Physiol., 37: 91. 
BATES, M.

1964 - The Land and Wildlife of South America. New Yo:k, Time Inc. (Life Nature Library).

BENNETT, M.V.L.

1970 - Comparati/e Physiology: electric organs. Ann. Rev. Physiol., 32: 451-528.

BLACK-CLEWORTH, P.

1970 - The role of electric discharges in the non. reproductive social behavior of Gymnotus carapo. Anim. Behav. Monogr., 3: 1-77.

BULLOCK, T.H

1974 - Specialized receptors in lower vertebrates. An essay on the discovery of sensory re. ceptors and the assignment of their functions together with an introduction to electroreceptors. In: Handbook of Sensory Physiology, 3(3) New York, A. Fessard \& Springer-Veriag

Bullock, T.H.; Hamstra, JR., R.H. \& SCheich, H.

1972a - The jamming avoidance response of himgh frequency electric fish. I. General features. J. Comp. Physiol., 77: 1-22.

$1972 \mathrm{~b}$ - The jamming avoidance response of high frequency electric fish. II. Quantitative aspects. J. Comp. Physiol., 77: 23-48.

Fessard, A.

1974 - Electroreceptors and Other Specialized Receptors in Lower Vertebrates. Handbook of Sensory Physiology, 3(3) New York, Springer-Veriag .

Hagiwara, S. \& MORITA, H.

1963 - Coding mechanisms of electroreceptor fibers in some electric fish. J. Neurophysiol., 26: $551-567$.

HEILIGENBERG, W.

1973 - Electrolocation of objects in the electric fish, Eigenmannia (Rhamphichthyidae, Gym. notoidei). J. Comp. Physiol., 87: 137-164.

1974 - Electrolocation and jamming avoidance in a Hypopygus (Rhamphichthyidae, Gymnotoidei), an electric fish pulse-type discinarge. J. Comp. Physiol., 9-: 223-240.

Hetligenberg, W. \& Bastian, J.

1977 - Species specificity of electric organ discharges in sympatric gymnotoid fisn of the Rio Negro and Solimōes/Brasil. J. Behav. Ecol. Sociobiol., (inpress).

HOPKINS, C.D.

1973 - Lightning as background noise for communication among electric fish. Nature, 222: 268-270.

1974a- Electric communication: Function in the social behavior of Eigenmannia virescens. Behavior, 50: 270-305.

$1974 \mathrm{~b}$ - Electric communication in the reproductive behavior of Sternopygus macrurus (Gymnotoidei). A. Tierpsychol., 35: 518-535. 1974c- Electric communication in fish. American Scientist, 62: 426-437.

Hopkins, C.D. \& Heil.tgenderg, W.

1977 - Evolutionary designs for electric signals and electroreceptors in gymnotoid fishes of Surinam. J. Behav. Ecol. Sociobiol. (in press).

KALMIJN, A.J.

1971 - The electric sense of sharks and rays. J Exp. Biol., 55: 371-383.

1974 - The role of electroreceptors in the animal's life. The detection of electric fields from inanimate and animate sources other than electric organs. In: Handbook of Sensory Physiology, 3(3) New York, Springer-Verlag.

Kirschbaum, F.

1975 - Environmental factors control the periodical reproduction of tropical electric fish Experientia, 31: 1159-1160.

KNÖPPEL, H.A.

1970 - Food of central Amazonian fishes. Contri. bution to the nutrient-ecology of Amazonian rain-forest-streams. Amazoniana, 2: 257-352.

LissmanN, H.W.

1958 - On the function and evolution of electric organs in fish. J. Exp. Biol., 35: 156-191.

Lissmann, H.W. \& Schassmann, H.O.

1965 - Activity rhythm of an electric fish, Gymnorhamphichthys hypostomus. Z. Vergl. Phy. siol., 51: 153-171.

MACO-LeCCIA, F.

1976 - Los peces Gymnotiformes de Venezuela: un estudio preliminar para la revisión del grupo em la América del Sur Tesis Doctoral. Univ. Central de Venezuela, Caracas, 376pp. 107 figs., 26 tables.

SCHEICH, H. \& BULLOCK, T.H.

1974 - The role of electroreceptor in the animal's life. The detection of electric fields. In: Handbook of Sensory Physiology, 3(3). New York, A. Fessard, ed. Springer-Verlag.

Schwassmann, H.O.

1971 -- Circadian activity patterns in gimnotid electric fish. In: Biochronometry $M$. Menaker, ed. Washington, D. C. Nat. Acad. Sci., pp 189-199.

Sterba, G.

1963 - Freshwater Fishes of the World. New York, Viking Press.

Szaвo, T.

1974 - Anatomy of the specialized lateral line organs of electroreception. In: Handbook of Sensory Physiology, 3(3). A. Fessard, ed. New York, Springer-Verlag.

(Aceito para publicação em 22/02/79) 